\title{
Nanoscience and the nano-bioelectronics frontier
}

\section{Citation}

Duan, Xiaojie, and Charles M. Lieber. 2015. "Nanoscience and the Nano-Bioelectronics Frontier." In Nano Research 8, no. 1: 1-22. doi:10.1007/s12274-014-0692-8.

\section{Published Version}

doi:10.1007/s12274-014-0692-8

\section{Permanent link}

http://nrs.harvard.edu/urn-3:HUL.InstRepos:20430658

\section{Terms of Use}

This article was downloaded from Harvard University's DASH repository, and is made available under the terms and conditions applicable to Open Access Policy Articles, as set forth at http:// nrs.harvard.edu/urn-3:HUL.InstRepos:dash.current.terms-of-use\#OAP

\section{Share Your Story}

The Harvard community has made this article openly available.

Please share how this access benefits you. Submit a story.

\section{Accessibility}




\title{
Nanoscience and the Nano-Bioelectronics Frontier
}

Xiaojie Duan $^{1}$ and Charles M. Lieber ${ }^{2,3}$

${ }^{1}$ Department of Biomedical Engineering, College of Engineering, Peking University, Beijing 100871, China

${ }^{2}$ Department of Chemistry and Chemical Biology, Harvard University, Cambridge, MA 02138 USA

${ }^{3}$ School of Engineering and Applied Sciences, Harvard University, Cambridge, MA 02138 USA

Address correspondence to Xiaojie Duan, xjduan@pku.edu.cn; Charles M. Lieber, $\underline{\mathrm{cml} @ \mathrm{cmliris} . h a r v a r d . e d u}$

\begin{abstract}
This review describes work presented in the 2014 inaugural Springer-Tsinghua Nano Research Award lecture, as well as current and future opportunities for nanoscience research at the interface with brain science. First, we briefly summarize some of the considerations and the research journey that has led to our focus on bottom-up nanoscale science and technology. Second, we recapitulate the motivation for and our seminal contributions to nanowire-based nanoscience and technology, including the rational design and synthesis of increasingly complex nanowire structures, and the corresponding broad range of 'applications' enabled by the capability to control structure, composition and size from the atomic level upwards. Third, we describe in more detail nanowire-based electronic devices as revolutionary tools for brain science, including (i) motivation for nanoelectronics in brain science, (ii) demonstration of nanowire nanoelectronic arrays for high-spatial/high-temporal resolution extracellular recording, (iii) the development of fundamentally-new intracellular nanoelectronic devices that approach the sizes of single ion channels, (iv) the introduction and demonstration of a new paradigm for innervating cell networks with addressable nanoelectronic arrays in three-dimensions. Last, we will conclude with a brief discussion of the exciting and potentially transformative advances expected to come from work at the nanoelectronics-brain interface.
\end{abstract}

\section{Keywords}

One-dimensional materials, two-dimensional materials, nanowires, carbon nanotubes, bottom-up paradigm, nanoelectronics, nanoelectronic arrays, neural probes, electrophysiology, neural circuits, brain activity map, chronic recording and stimulation, brain-machine interfaces 


\section{Introduction and personal note $(\mathrm{cml})$}

It was a great honor to receive the 2014 inaugural Springer-Tsinghua Nanoresearch Award. At the outset I would like to acknowledge all of my coworkers who have contributed to the research recognized by this award, and give special thanks, as part of the 2014 SINO-USA meeting, to the many Chinese graduate students, postdoctoral fellows and visitors who I have had the pleasure to work with and who have made pioneering contributions to our research in nanoscience (see Addendum Table-1). Given the pedagogical nature of the SINO-USA meeting, I will begin this review with a brief account of some of the considerations and pathway that has led to our focus on bottom-up nanoscale science and technology (section-1), review succinctly the motivation for and our seminal contributions to nanowire-based nanoscience and technology (section-2), and finally we will discuss very exciting evolution of this work in one current direction: the interface between nanoelectronics and brain science where we see huge potential for future (section-3).

Our research focus on nanoscience can be traced to an early interest in understanding local nanoscale structural and electronic effects of doping and chemical substitution in two-dimensional (2D) metal dichalcogenide and layered metal oxide materials using scanning tunneling microscopy/spectroscopy (STM/STS), especially with respect to the fascinating charge-density-wave and superconducting phase transitions observed in these materials [1-13]. This interest in understanding the behavior of lowdimensional materials from a local nanoscale perspective led naturally to an interest in fullerene based solids, which when doped with alkali metals, exhibited unusually high-temperature superconductivity compared to the corresponding alkali metal-doped graphite/graphene parent material [14-19]. Our lowtemperature STM/STS studies provided unique insight into the mechanism of superconductivity [16,17], but also highlighted the need to tune chemically the clusters, which we achieved through synthesis of ${ }^{13} \mathrm{C} /{ }^{12} \mathrm{C}$ isotope-substituted $\mathrm{C}_{60}[18,19]$, to better understand superconductivity in these nanoclusterderived materials.

The above studies began an emphasis towards controlled-synthesis of functional nanoscale building blocks, although the Lieber group remained focused much of the 1990s on characterization of nanoscale and low-dimensional materials [20-28], as well as developing new methods for characterizing fundamental chemical, electrical and mechanical properties of nanoscale structures [29-33]. STM/STM was used to demonstrate experimentally for the first time the diameter-chirality dependent electronic properties of carbon nanotubes [20,21], and also a number of more subtle and interesting structureelectronic characteristics of single-walled nanotubes [22-28].

At the same time and in-line with asking myself the question: "How could we use these nanostructures to create or do something unique and different from what was possible by top-down fabrication?" we realized it was also important to understand their conductivity and mechanical properties. To this end we carried out some of the first measurements of the single carbon nanotube conductivity [31], and the first measurements of the elastic modulus and strength of individual carbon nanotube and carbide nanowires [32] by developing new scanning probe microscopy methods. These measurements of the electrical-mechanical properties, then led to realization that nanotubes could function uniquely as bottom-up organized electromechanical devices, where we proposed and demonstrated for the first time a carbon nanotube nanotweezers [34], which was capable of grasping and 
manipulating nanoclusters, and a nanotube-based nonvolatile random access memory [35], which led to a successful company producing radiation hard memory chips [36].

Despite these significant advances in characterization and 'applications' of carbon-based nanostructures, we recognized early on key limitations that had to be overcome for developing our vision of the bottom up paradigm for nanoscience, including (i) the lack of a selective synthesis of semiconducting and metallic carbon nanotubes, and more generally, (ii) the difficulty to elaborate the structure, composition and morphology in general manner by design. In this regard, we began in the early-to-mid 1990s a concerted effort focused on the synthesis of one-dimensional (1D) nanoscale building blocks in which structure, composition, size and physical properties could all be controlled rationally during synthesis [37-91]. In the next section, we briefly review the motivation for developing our vision bottom-up paradigm and our focus 1D nanowire building blocks.

\section{Bottom-up paradigm and nanowire functional building blocks}

In the bottom-up paradigm, precisely synthesized nanoscale building blocks are assembled into functional structures, much like the way nature uses proteins and other macromolecules to construct complex biological systems [42,69-71,73,86,92-110]. The bottom-up approach has the potential to go far beyond the limits and functionality of top-down technology by defining key nanometer-scale metrics through synthesis and subsequent assembly, and not by lithography. In addition, the bottom-up approach enables new concepts for nanoscale structures, functional units and systems, and thus offers the promise of creating technologies that might previously have been more the realm of science fiction versus scientific reality. Several examples of such opportunities at the interface between nanoscience and biology will be described below in section-3.

Within the context of the bottom-up paradigm, our focus on 1D nanostructures was motivated early on by several important basic concepts. First, 1D nanostructures represent the smallest dimension structure that can efficiently transport information, including electron and hole carriers, photons and magnetic excitations, and thus are ideally suited to the critical and ubiquitous task of moving and manipulating information in integrated nanoscale systems. Second, 1D nanostructures can also exhibit device function, and thus can be exploited as both the wiring and device elements in architectures for functional nanosystems [92-100].

Central to the bottom-up approach is the rational synthesis of nanoscale building blocks with precisely controlled and tunable chemical composition, structure, size, and morphology since these characteristics determine their corresponding physical properties. Specifically, the capability to create new nanostructures and assemblies with tunable composition and structure on many length scales is critical to and drives the scientific breakthroughs that enable revolutionary advances and future technologies. In other words, rather than exploring a single nanomaterial, many of the greatest opportunities lay with systems in which the structure, composition and corresponding properties can be tuned. 
In this regard, semiconductor nanowires serve as one of the most powerful platforms available today in nanoscience given that it is now possible to design structures ab initio, and synthetically realize these structures with the structure and composition controlled from the atomic scale and up. These capabilities - to design and synthetically realize complex nanowire materials - is almost unique among nanomaterials, and enables systems or building blocks to be created, which have predictable physical properties and which enable for testing fundamental limits of performance. It is also possible to assemble hybrid or multicomponent functional materials in novel environments using these diverse nanowire building blocks, allowing for rational exploration of the possible applications of multicomponent materials. With these characteristics and capabilities, nanowires are ideal building blocks for exploring what is possible in nanoscience and also creating new technologies. This has been our focus over the past decade and continues to be so as we move forward in our research today.

An overview of the current status of nanowire synthesis is shown in Figure 1, which highlights five distinct structural classes available today. The basic semiconductor nanowire structure (center, Fig. 1) consists of a uniform composition, one-dimensional (1D) structure with diameter typically in the range of $3-500 \mathrm{~nm}$. We first reported that metal nanoparticles could be used as 'catalysts' within the general context of a vapor-liquid-solid growth mechanism to control the critical nucleation and subsequent elongation steps of nanowire growth $[39,40]$. Using this approach, we showed early on that a broad range of semiconductor nanowires with homogeneous composition and single-crystal structures could be prepared from the main group of the periodic table $[40,42,43]$. In addition, this work on homogenous composition nanowire materials demonstrated that the diameter was controlled by the size of the nanoparticle 'catalyst', as suggested by the growth model, with diameters as small as $3 \mathrm{~nm}$ realized $[47,48,55]$, that nanowire length was proportional to growth time [48] and, significantly, that specific dopants could be incorporated into nanowires to control their electronic properties [47,92-94]. The ability to control the fundamental electronic and optical properties of nanowires through doping has been central to much of the success of researchers worldwide in developing active electronic and optoelectronic nanodevices.

With the nanocluster-catalyzed growth formalism in hand, it has been possible to elaborate the basic nanowire structure in many new and sometimes unexpected directions. In early 2002, my group [50] and several other laboratories around the world first demonstrated that it was possible to synthesize structures in which the composition and/or doping were modulated along the nanowire axial or growth direction (lower left, Fig. 1). Later that same year [52], we showed that composition and/or dopant modulation could be encoded in the radial direction with core/shell nanowire structures (upper left, Fig. 1). This core/shell nanowire structural motif has proven exceptionally powerful for a wide-range of electronic and photonic device applications [61,63,65,67-71,74-76,78,80,87,91]. A third basic motif involves the synthesis of branched or tree-like nanowire structures using sequential nucleation of nanowires from a nanowire backbone (upper right, Fig. 1), where each generation of nanowire branches can have a unique diameter and composition $[56,85]$.

Most recently, we have shown that one can break from linear 1D structures and the branched-linear motif, to one in which topological centers are synthetically introduced in a controlled manner (lower right, Fig. 1) [83]. In this latter direction, we demonstrated that iterative control over nucleation and growth leads to kinked or zigzag nanowires in which the straight sections are separated by triangular 
joints and where doping can be varied at these topologically-defined points. Moreover, new work [59] has shown that it is possible to control the 'stereochemistry' of adjacent kinks in a manner that allows the synthesis of increasingly complex two- and three-dimensional structures akin to organic chemistry, thus opening up a great opportunity for the future in terms of designed synthesis.

This broad range of increasingly complex nanowire building blocks has enabled researchers worldwide to explore and develop a wide-range of science and technology as indicated in Figure 2. For example, nanowire building blocks have provided a unique platform for seminal advances in (i) electronic devices, assembled electronic circuits and nanoprocessors [47,50,52,53,57,62,66$69,74,76,92,94-96,98,101-103,106-108,110-118]$, (ii) quantum physics [63,81,119-127], (iii) nanophotonic devices and circuits [44,50-53,61,65,69,70,72,78,85,92,104,115,128-137], (iv) nanoenabled energy [75,80,87,138-143], and (v) biology and nanomedicine [84,86,90,144-170]. Within the constraints of time and space we will focus our discussion of recent and emerging work on only a subset of one area - the interface between nanobiolectronics and neural systems - in section-3 below.

\section{Nano-bioelectronics for brain activity recording and mapping}

The brain consists of densely wired circuits made of heterogeneous cells [171]. These circuits are organized through synaptic connections, which exhibit time- and learning-dependent strengths and connectivity, into hierarchical networks. The function of neural circuits arises from the coordinated activity of large numbers of neuron operating on spatial and temporal scales that span multiple orders of magnitudes. Therefore, the development of tools with high spatial and temporal precision as well as scalability to make highly parallel measurements are a priority to investigate and understand the function of neural circuits and the brain.

Nano-bioelectronic devices, which have the capability to sense and record electrical and chemical changes [84,86,90,144-168], provide unique opportunities for brain activity recording and mapping (Fig. 3). First, nano-bioelectronic devices enable the study of the neural circuits at both cellular and subcellular resolution. This is especially important for investigating small subcellular structures such as the neuronal dendrites and synapses [172]. Second, the small size of nanoscale devices in nanobioelectronics allows for high scalability in terms of the recording density and total number of the recording sites. Third, the small device size can minimize the perturbation of neurons and neural circuits. Fourth, the demonstrated capability to present nanoelectronic devices as highly-flexible networks promises better biocompatibility compared to conventional rigid structures [173], which can allow for long-term stable recording studies as well as the development of new brain-machine interfaces.

Nano-bioelectronics, especially devices and arrays based on functional free-standing nanoscale building blocks such as nanowires, has already made key advances in studies of neurons and neural circuits relevant to understanding the brain $[150,155,165]$. The capability of using nanowire and other building blocks in a bottom-up/top-down scheme allows for great versatility in the fabrication of recording probes. For example, the nanoelectronic devices can not only be assembled onto flexible plastic substrates leading to conformal recording from the brain surface [174], but also seamless interpenetration of nanoelectronics in the three-dimensional (3D) space of artificial tissue constructs so 
that 3D mapping of neural activity is possible [162, 163]. The well-established control over nanowire structure, composition, size and morphology allow designed functions to be encoded during synthesis, thus enabling the hierarchical design of devices that can be used for both extracellular and intracellular recording [84, 150-157, 160-167]. Below we will briefly discuss representative work interfacing nanoelectronics with neural and related systems, with an emphasis on free-standing semiconducting nanowires based nanoelectronics.

Nanoscale field-effect transistors (FETs) using silicon nanowires (SiNWs) as semiconducting channels have been used to record extracellular action potentials from cultured rat cortical and hippocampal neurons (Fig. 4A) with unprecedented spatial resolution as early as 2006 [150]. The depolarization of cell membrane during action potential firing results in negative charging of the extracellular space around the nanowire which leads to the conductance change of the FET devices. The signals recorded by the SiNW FETs were in good temporal correlation with the intracellular action potentials recorded by a glass micropipette [150]. A key advantage of this work using SiNW FET nanobioelectronics is that it was possible to record action potentials from the cell body and much smaller neurite projections, where conventional microelectrode arrays (MEAs) typically cannot record from the neurites due to the large electrode size. This highlights the higher spatial precision and resolution of nanoscale devices in neural activity recording. It should be pointed out that the small active junction area for nanowire/axon interfaces, $0.01-0.02 \mu \mathrm{m}^{2}$, is at least two orders of magnitude smaller than microfabricated electrodes and planar FETs [175]. This higher spatial precision, together with the capability of making higher density device array, makes efficient multiplexed recordings from single neurons possible. As shown in Fig. 4A, patterning yielded growth of neurites across three of the four peripheral SiNW FET devices in an array, while signals were recorded from these three SiNW FETs but not the device without a crossing neurite following stimulation. Importantly, our multiplexed recording carried out in this way proved the capability of nanoscale devices for high-density neural activity mapping. These capabilities provide one of the very first examples of the power and potential importance of nanodevices for high-resolution neural mapping as very recently set forth as a high priority of the BRAIN initiative.

We subsequently extended our seminal work on cultured neurons to map neural circuit activity in acute brain slices in 2010 [155] to demonstrate the unique capabilities of high density SiNW FET arrays. For example, an optical image of an oriented acute brain slice (Fig. 4B, left), which was placed on top of the SiNW FETs device array, shows the lateral olfactory tract (LOT) and the pyramidal neuron layers. Following stimulation at different points within the LOT, excitatory postsynaptic potentials (EPSPs) and population spikes (p-spikes) can be recorded from the SiNW FET array located under the pyramidal neuron cell circuit [155]. Significantly, differences in the recorded signal were observed between devices with spacing as small as $5 \mu \mathrm{m}$, which exceeds substantially that reported in previous MEAs and planar FETs measurement [176-179]. The differences lie in the amplitude and shape of both the EPSP and p-spike, which reflect the different change of the extracellular potential at different local regions of pyramidal cells, corresponding to current sources and sinks in the neural network. This difference demonstrates the high spatial resolution of the SiNW FET recording, which was then exploited to map the neural connectivity in the olfactory cortex. Representative data recorded from eight devices following stimulation at eight different spots (a-h, Fig. 4B, left) in the LOT showed distinct responses 
(Fig. 4B, right). Specifically, the 2D maps from the SiNW FET array resolved clearly the heterogeneous activity of the neural circuit $[155,165]$.

The capability to control the structure, morphology, composition and corresponding function of nanowire building blocks provides great opportunities to design and fabricate devices with unique 3D configurations that can be used for high-resolution intracellular recording with minimal invasiveness. Compared to extracellular recording, intracellular recording can provide more information, such as the subthreshold transmembrane potential change associated with synaptic interactions [180]. Conventional intracellular recording is relatively invasive to neurons because of the large probe sizes of patch-clamp micropipettes, and leakage of solution from these probes into the cells being studied [180]. Furthermore, the complexity of the micromanipulator based recording makes it difficult to perform simultaneous recordings at a large number of sites [180]. One effective approach to overcome the above limitations of conventional intracellular recording probes and also to enable new capabilities is to develop nanoscale intracellular probes with active FET detection elements. However, FETs have conventionally existed in a linear geometry with source/drain connections that preclude access to the inside of cells [165].

We have for the first time overcome this previous hurdle to exploiting FETs for intracellular recording using two novel but general classes of nanoprobes based on kinked nanowire FETs [83, 84, 88] and nanotube coupled FETs [160, 161]. In the first approach, a kink structure and the voltage-sensitive active transistor channel (a lightly doped segment) are designed and rationally-encoded into the nanowire by synthesis using our nanocluster-catalyzed growth approach (upper image, Fig. 5A) [83, 84]. A cell probe is fabricated by connecting the two heavily doped arms of the kinked nanowire probe with strained metal interconnects that bend upwards to present the kinked tip to open 3D space (lower image, Figure 5A) above the device chip. After cell membrane penetration with the kink tip, the nanoscale FET accesses the intracellular space and can record the transmembrane potential change from inside the cell.

Another approach takes advantage of the hierarchical design of the nanowire-nanotube heterostructures. A vertical or nearly vertical electrically insulating $\mathrm{SiO}_{2}$ nanotube is integrated on top of the SiNW FET channel. After the nanotube tip penetrates the cell membrane, the cytosol fills the nanotube and the underlying FET can thereby record potential changes within the cell. In this way, the probe, which is termed the branched intracellular nanotube FET (BIT-FET), can record the intracellular transmembrane potential change or action potentials [160]. Our BIT-FET design uses the tip of controlled-diameter nanotubes to interface to and probe intracellular regime. It allows for the smallest absolute probe size possible for any electrophysiology tool reported to date. For example, BIT-FET devices with sub-10 nm diameter nanotubes have been fabricated and demonstrated to be capable of intracellular recording (Fig. 5B, 167). The small diameters accessible with the BIT-FET suggest that it will be minimally invasive with ultra-high spatial resolution, and thus, could probe the smallest cellular structures, including neuron dendrites and dendritic spines, which are difficult by means of conventional electrophysiology [172,181,182]. In addition, this design is compatible with large-scale, high-density, planar nanoscale FET arrays, which makes it possible to do parallel recordings from large numbers of sites with much higher spatial resolution than with other probe [165].

Our concept of using nanotube coupled FETs for intracellular recording can be extended to other designs. For example, we have shown that the nanotube can be made of semiconducting silicon such that 
the nanotube itself can function as the active channel of the FET detector. The source and drain electrodes are fabricated on one end of the nanotube, while leaving the other end free for cell membrane penetration. The cytosol, which fills the nanotube after membrane penetration, can gate the FET from inside the nanotube which enables the recording of the intracellular potentials [161, 165, 182].

The kinked nanowire structure has also been extended, including the development and demonstration of free-standing 3D probes and zero-degree kinked nanowire probe tips that can better access the interior of a cell or tissue [90]. Nanowire structures in which two-kink nanowire devices were juxtaposed in a single W-shape with nanoscale FETs integrated at the tips of each of the kinked regions were also achieved using this strategy [90]. By encoding multiple nanoscale FETs in these complex structures and precisely controlling the nanowire/cell interface, these probes offer the potential for relatively high-density multiplexed intracellular recording and/or simultaneous recording of both intraand extracellular signals, which is unique compared to other passive recording devices [182]

For these nanoscale electronic intracellular probes, cell membrane penetration represents a critical step for successful, stable and minimally invasive recording. In contrast to mechanical suction or insertion used with conventional microscale tools, we have shown that phospholipid functionalization facilitates spontaneous membrane penetration with our nano-bioelectronic probes to yield a tight, highresistance probe/membrane seal (Fig. 5C). Using this unique biomimetic approach, it has been possible to record stable full-amplitude intercellular action potential signals from individual cardiomyocyte cells with both kinked nanowire and nanotube based probes [83, 84, 88, 160, 161]. For example, the transition from extracellular spikes to full-amplitude intracellular action potential peaks (with a concomitant decrease in baseline potential) occurs without application of an external force (Fig. 5D). Notably, the recorded intracellular action potential peaks exhibit all of the details of standard cardiac action potentials [183]. Furthermore, the probes can be retracted from the cell and re-enter at approximately the same position on the same cell to record intracellular action potentials multiple times without affecting the cell. This represents another unique characteristic of our nano-bioelectronic probes, and highlights their minimal invasiveness, reliability and robustness, which are all important characteristics for long-term, stable recording.

Simultaneous, multisite intracellular recording of action potentials from both single cells and cell networks can be readily achieved by interfacing these independently addressable nano-bioelectronic devices with cells. Our reported multiplexed measurements [160, 161] demonstrate the substantial potential of these probes for high spatiotemporal resolution and large-scale brain activity mapping. The small size of these nanoscale probes not only makes it possible for unprecedented high-density device arrays, which are critical for cellular and even sub-cellular resolution mapping, but also yields minimal perturbation of the cells and/or tissues under study. We believe that the nanoscale probes discussed here represent great candidates for use in brain activity mapping and related research [184] and can extend substantially the scope of fundamental and applied electrophysiology studies [172].

The nanowire building blocks also allow for the design and fabrication addressable nanoelectronic device networks that can be seamlessly merged with living tissues in 3D. Conceptually, this integration of nanoelectronics with cell networks can be achieved in three basic steps (Fig. 6A). First, the addressable nanoelectronic network is fabricated in 2D by standard methods on a sacrificial layer (step 
A). A variety of functional nanowire nanoelectronic elements can be incorporated including sensors [94, 151], light-emitting diodes [65], logic and memory [96, 112], and energy production and storage devices. Second, the sacrificial layers is removed to release the nanoelectronic network and yield 3D, freestanding nanoelectronic scaffolds (nanoES) (step B). Third, cells are seeded and cultured in the nanoES to yield 3D nanoelectronic-tissue hybrids (step C) $[162,163]$. In this new paradigm, a macroporous electronic network (e.g., >95\% porosity) is critical to enable 3D interpenetration of cells in the final hybrid tissue. Moreover, to mimic the well-studied scaffold materials used for tissue engineering, the nanoES structural elements have dimensions of nano- to micrometer, with mechanical properties similar to those of natural tissue. These unique structural and mechanical characteristics are distinct from all other types of electronics used to date for interfacing and insure good biocompatibility.

Figure 6B shows a 3D scaffold with interconnected and addressable nanowire FET sensors meeting our design concepts, where the 3D structure was self-organized by introducing strained elements during 2D fabrication. Alternatively, 2D macroporous nanoelectronic networks can be transformed into 3D nanoES by directed assembly and manual manipulation. The nanoES can be used for 3D culture of neurons, cardiomyocytes, and smooth muscle cells. For example, a reconstructed 3D confocal micrograph from a two-week culture of rat hippocampal neurons within a 3D nanoES (Fig. 6C) shows neural network with a high density of spatially interconnected neurites interpenetrating the nanoES [162]. Cytotoxicity tests demonstrated that the nanoES has little or no effect on cell viability, and moreover, electrical measurements showed that SiNW FET device elements were stable for at least 12 weeks. The embedded devices in the nano ES can successfully record action potentials from the artificial tissue constructs, which proves their unique capability for 3D activity mapping. Figure 6D shows an example of multiplexed extracellular recording from a coherently beating nanoES/cardiac cyborg tissue, where the recording demonstrates sub-millisecond temporal resolution with separations up to $6.8 \mathrm{~mm}$ within the 3D innervated tissue sample. The capability of the nanoES for long-term culture and monitor of the artificial tissue enables a number of in vitro studies, including drug screening assays, and also opens up novel opportunities for active implants and new types of chronic recording probes, where the coupling extends from the surface to inside the biological samples, and is thereby very distinct from either engineered tissue [185,186] or flexible electronics $[152,174,187]$.

The above studies described in section-3 demonstrate that nanowire-based nano-bioelectronics represents a new and powerful platform for neural activity recording and mapping. As we look to the future, we can synthesize many of these nano-bioelectronics which advances in new ways to make transformative changes for in-vivo brain studies. Specifically, we propose to exploit the unique flexibility of macroporous nanoelectronic networks [162, 163], which will reduce inflammatory response in the brain and increase the stability of long-term chronic recordings [173], as well as the potential of these networks for high spatiotemporal resolution and high-density recording as a revolutionary approach for in-vivo electrical brain activity mapping (Fig. 7). The flexibility of the macroporous nanoelectronic network (Fig. 7A) makes it difficult to insert directly into the brain compared to rigid (but ultimately invasive) probes, although we envision two general strategies (Fig. 7B, C) for implanting this network that can take full-advantage of its unique capabilities for in-vivo neural activity recording and mapping. For example, the flexible nanoelectronic device network can be transferred to the surface of a biodegradable polymer layer with a more rigid structure such that direct 
mechanical insertion is used as with conventional neural probes, but then the sacrificial support dissolves such that rigid structure is removed and the nanoelectronic device network remains inside the brain ultimately yielding a seamless nanoelectronics/neural network interface. Alternatively, the highlyflexible nanoelectronic network is injected via a syringe needle directly into the brain (Fig. 7B), in a manner similar to drugs, viruses, and stem cells used in neurobiology studies. Post-injection, the nanoelectronic network is expected to yield a seamless nanoelectronics/neural network interface (Fig. 7C). We believe that this new paradigm for integrating macroporous nanoelectronic networks within the brain, provides a leap forward in capabilities for mapping and modulating brain activity over long time periods in mature and developing systems. And it will open unique opportunities for treatment of neurological (e.g., epilepsy) and neurodegenerative (e.g., Parkinson's) diseases, and will provide a paradigm change for brain-electronics interface that could revolutionize the power and capabilities of brain-machine interfaces.

\section{References}

1. Wu, X. L.; Zhou, P.; Lieber, C. M. Surface electronic properties probed with tunneling microscopy and chemical doping. Nature 1988, 335, 55-57.

2. Wu, X. L.; Zhou, P.; Lieber, C. M. Determination of the local effect of impurities on the chargedensity-wave phase in $\mathrm{TaS}_{2}$ by scanning tunneling microscopy. Phys. Rev. Lett. 1988, 61, 26042607.

3. Wu, X. L.; Lieber, C. M. Hexagonal domain-like charge density wave phase of $\mathrm{TaS}_{2}$ determined by scanning tunneling microscopy. Science 1988, 243, 1703-1705.

4. Wu, X. L.; Lieber, C. M. Scanning tunneling microscopy investigations of a new charge density wave phase in niobium-doped tantalum disulfide. J. Am. Chem. Soc. 1989, 111, 2731-2733.

5. Wu, X. L.; Lieber, C. M.: Ginley, D. S.; Baughman, R. J. Scanning tunneling microscopy investigations of the local structure of $\mathrm{Tl}_{2} \mathrm{Ba}_{2} \mathrm{CaCu}_{2} \mathrm{O}_{8}$ single crystals. Appl. Phys. Lett. 1989, 55, 2129-2131.

6. Wu, X. L.; Lieber, C. M. Direct observation of growth and melting of the hexagonal-domain charge-density-wave phase in $1 T-\mathrm{TaS}_{2}$ by scanning tunneling microscopy. Phys. Rev. Lett. 1990, 64, 1150-1153.

7. Wu, X. L.; Zhang, Z.; Wang, Y. L.; Lieber, C. M. Structural and electronic role of lead in $(\mathrm{PbBi})_{2} \mathrm{Sr}_{2} \mathrm{CaCu}_{2} \mathrm{O}_{8}$ superconductors by STM. Science 1990, 248, 1211-1214.

8. Zhang, Z.; Wang, Y. L.; Wu, X. L.; Huang, J.-L.; Lieber, C. M. Electronic effect of lead substitution in single-crystal $\mathrm{Bi}(\mathrm{Pb})-\mathrm{Sr}-\mathrm{Ca}-\mathrm{Cu}-\mathrm{O}$ superconductors determined by scanning tunneling microscopy. Phys. Rev. B 1990, 42, 1082-1085.

9. Dai, H.; Chen, H.; Lieber, C. M. Weak pinning and hexatic order in a doped two-dimensional charge-density-wave system," Phys. Rev. Lett. 66, 3183-3186 (1991). 
10. Wu, X. L.; Lieber, C. M. Scanning tunneling microscopy studies of low-dimensional materials: probing the effects of chemical substitutions at the atomic level. Acc. Chem. Res.1991, 24, 170177.

11. Dai, H.; Lieber, C. M. Solid-hexatic-liquid phases in two-dimensional charge-density waves. Phys. Rev. Lett. 1992, 69, 1576-1579.

12. Zhang, Z.; Lieber, C. M. Measurement of the energy gap in oxygen-annealed $\mathrm{Bi}_{2} \mathrm{Sr}_{2} \mathrm{CaCu}_{2} \mathrm{O}_{8+\delta}$ high- $T_{c}$ superconductors by tunneling spectroscopy. Phys. Rev. B 1993, 47, 3423-3426.

13. Dai, H.; Lieber, C. M. Scanning tunneling microscopy studies of low-dimensional materials: Charge density wave pinning and melting in two dimensions. Ann. Rev. Phys. Chem. 1993, 44, 237-263.

14. Kelty, S. P.; Chen, C. C.; Lieber, C. M. Superconductivity at $30 \mathrm{~K}$ in caesium-doped $\mathrm{C}_{60}$. Nature 1991, 352, 223-225.

15. Chen, C. C.; Kelty, S. P.; Lieber, C. M. $\left(\mathrm{Rb}_{\mathrm{x}} \mathrm{K}_{1-\mathrm{x}}\right) \mathrm{C}_{60}$ Superconductors: formation of a continuous series of solid solutions. Science 1991, 253, 886-888.

16. Zhang, Z; Chen, C. C.; Kelty, S. P.; Dai, H.; Lieber, C. M. The superconducting energy gap of $\mathrm{Rb}_{3} \mathrm{C}_{60}$. Nature 1991, 353, 333-335.

17. Zhang, Z; Chen, C. C.; Lieber, C. M. Tunneling spectroscopy of $\mathrm{M}_{3} \mathrm{C}_{60}$ superconductors: The energy gap, strong coupling, and superconductivity. Science 1991, 254, 1619-1621.

18. Chen, C. C.; Lieber, C. M. Isotope effect and superconductivity in metal-doped $\mathrm{C}_{60}$. Science 1993, 259, 655-658.

19. Chen, C. C.; Lieber, C. M. Synthesis of pure ${ }^{13} \mathrm{C}_{60}$ and determination of the isotope effect for fullerene superconductors. J. Am. Chem. Soc. 1992, 114, 3141-3142.

20. Zhang, Z.; Lieber, C. M. Nanotube structure and electronic properties probed by scanning tunneling microscopy. Appl. Phys. Lett. 1992, 62, 2792-2794.

21. Odom, T. W.; Huang, J. L.; Kim P.; Lieber, C. M. Atomic structure and electronic properties of single-walled carbon nanotubes. Nature 1998, 391, 62-64.

22. Kim P.; Odom, T. W.; Huang, J. L.; Lieber, C. M. Electronic density of states of atomically resolved single-walled carbon nanotubes: Van Hove singularities and end states. Phys. Rev. Lett. 1999, $82,1225-1228$.

23. Venkataraman, L.; Lieber, C. M. Molybdenum selenide molecular wires as one-dimensional conductors. Phys. Rev. Lett. 1999, 83, 5334-5337.

24. Odom, T. W.; Huang, J. L.; Cheung, C. L.; Lieber, C. M. Magnetic clusters on single-walled carbon nanotubes: The Kondo effect in a one-dimensional host. Science 2000, 290, 1549-1552. 
25. Ouyang, M.; Huang, J. L.; Cheung, C. L.; Lieber, C. M. Atomically resolved single-walled carbon nanotube intramolecular junctions. Science 2001, 291, 97-100.

26. Ouyang, M.; Huang, J. L.; Cheung, C. L.; Lieber, C. M. Energy gaps in "metallic" single-walled carbon nanotubes," Science 2001, 292, 702-705.

27. Ouyang, M.; Huang, J. L.; Lieber, C. M. One-dimensional energy dispersion of single-walled carbon nanotubes by resonant electron scattering. Phys. Rev. Lett. 2002, 88, 066804 1-4.

28. Ouyang, M.; Huang, J. L.; Lieber, C. M. Scanning tunneling microscopy studies of the onedimensional electronic properties of single-walled carbon nanotubes. Annu. Rev. Phys. Chem. 2002, 53, 201-220.

29. Frisbie, C. D.; Rozsnyai, L. F.; Noy, A.; Wrighton, M. S.; Lieber, C. M. Functional group imaging by chemical force microscopy," Science 1994, 265, 2071-2074.

30. Noy, A.; Vezenov, D. V.; Lieber, C. M. Chemical force microscopy," Annu. Rev. Mater. Sci. 1997, 27, 381-421.

31. Dai, H.; Wong, E. W.; Lieber, C. M. Probing electrical transport in nanomaterials: Conductivity of individual carbon nanotubes. Science 1996, 272, 523-526.

32. Wong, E. W.; Sheehan, P. E.; Lieber, C. M. Nanobeam mechanics: Elasticity, strength and toughness of nanorods and nanotubes," Science 1997, 277, 1971-1975.

33. Wong, S. S.; Joselevich, E.; Woolley, A. T.; Cheung, C. L.; Lieber, C. M. Covalently functionalized nanotubes as nanometer probes for chemistry and biology. Nature 1998, 394, 5255.

34. Kim; P.; Lieber, C. M. Nanotube nanotweezers. Science 1999, 286, 2148 - 2150.

35. Rueckes, T; Kim, K; Joselevich, E.; Tseng, G. Y.; Cheung, C. L.; Lieber, C. M. Carbon nanotube-based nonvolatile random access memory for molecular computing," Science 2000, 289, 94-97.

36. Nantero: http://www.nantero.com/.

37. Dai, H.; Wong, E. W.; Lu, Y.; Fan, S.; Lieber, C. M. Synthesis and characterization of carbide nanorods. Nature 375, 769-772 (1995).

38. Wong, E. W.; Maynor, B. W.; Burns, L. D.; Lieber, C. M. Growth of metal carbide nanotubes and nanorods," Chem. Mater. 1996, 8, 2041-2046.

39. Lieber, C. M.; Morales, A. M.; Sheehan, P. E.; Wong, E. W.; Yang, P. One-dimensional nanostructures: Rational synthesis, novel properties and applications. Proceedings of the Robert A. Welch Foundation 40th Conference on Chemical Research: Chemistry on the Nanometer Scale 165-187 (Robert A. Welch Foundation, 1997).

40. Morales, A. M.; Lieber, C. M. A laser ablation method for the synthesis of crystalline semiconductor nanowires. Science 1998, 279, 208-211. 
41. Hu, J.; Ouyang, M.; Yang, P; Lieber, C. M. Controlled growth and electrical properties of heterojunctions of carbon nanotubes and silicon nanowires. Nature 1999, 399, 48-51.

42. Hu, J.; Odom, T. W.; Lieber, C. M. Chemistry and physics in one dimension: Synthesis and properties of nanowires and nanotubes. Acc. Chem. Res. 1999, 32, 435-445.

43. Duan, X.; Lieber, C. M. General synthesis of compound semiconductor nanowires. Adv. Mater. 2000, 12, 298-302.

44. Duan, X.; Wang, J.; Lieber, C. M. Synthesis and optical properties of gallium arsenide nanowires. Appl. Phys. Lett. 2000, 76, 1116-1118.

45. Wei, Q.; Lieber, C. M. Solution-based synthesis of magnesium oxide nanorods," Mat. Res. Soc. Symp. Proc. 2000, 581, 3-7.

46. Wei, Q.; Lieber, C. M. Synthesis of single crystal bismuth-telluride and lead-telluride nanowires for new thermoelectrical materials. Mat. Res. Soc. Symp. Proc. 2000, 581, 219-223.

47. Cui, Y.; Duan, X.; Hu, J.; Lieber, C. M. Doping and electrical transport in silicon nanowires. J. Phys. Chem. B 2000, 104, 5213-5216.

48. Cui, Y.; Lauhon, L. J.; Gudiksen, M. S.; Wang, J.; Lieber, C. M. Diameter-controlled synthesis of single-crystal silicon nanowires. Appl. Phys. Lett. 2001, 78, 2214-2216.

49. Gudiksen, M. S.; Wang, J.; Lieber, C. M. Synthetic control of the diameter and length of single crystal semiconductor nanowires. J. Phys. Chem. B 2001, 105, 4062-4064.

50. Gudiksen, M. S.; Lauhon, L. J.; Wang, J.; Smith, D.; Lieber, C. M. Growth of nanowire superlattice structures for nanoscale photonics and electronics. Nature 2002, 415, 617-620.

51. Gudiksen, M. S.; Wang, J.; Lieber, C. M. Size-dependent photoluminescence from single indium phosphide nanowires. J. Phys. Chem. B 2002, 106, 4036-4039.

52. Lauhon, L. J.; Gudiksen, M. S.; Wang, D.; Lieber, C. M. Epitaxial core-shell and core-multishell nanowire heterostructures. Nature 2002, 420, 57-61.

53. Zhong, Z.; Qian, F.; Wang, D.; Lieber, C. M. Synthesis of p-type gallium nitride nanowires for electronic and photonic nanodevices. Nano Lett. 2003, 3, 343-346.

54. Barrelet, C. J.; Wu, Y.; Bell, D. C.; Lieber, C. M. Synthesis of CdS and ZnS nanowires using single-source molecular precursors. J. Am. Chem. Soc. 2003, 125, 11498-11499.

55. Wu, Y.; Cui, Y.; Huynh, L.; Barrelet, C. J.; Bell, D. C.; Lieber, C. M. Controlled growth and structures of molecular-scale silicon nanowires. Nano Lett. 2004, 4, 433-436.

56. Wang, D.; Qian, F.; Yang, C.; Zhong, Z.; Lieber, C. M. Rational growth of branched and hyperbranched nanowire structures. Nano Lett. 2004, 4, 871-874. 
57. Greytak, A. B.; Lauhon, L. J.; Gudiksen, M. S.; Lieber, C. M. Growth and transport properties of complementary germanium nanowire field-effect transistors. Appl. Phys. Lett. 2004, 84, 41764178 .

58. Lauhon, L. J.; Gudiksen, M. S.; Lieber, C. M. Semiconductor nanowire heterostructures,” Phil. Trans. R. Soc. Lond. A 2004, 362, 1247-1260.

59. Wu, Y.; Xiang, J.; Yang, C.; Lu, W.; Lieber, C. M. Single-crystal metallic nanowires and metal/semiconductor nanowire heterostructures. Nature 2004, 430, 61-65.

60. Bell, D. C.; Wu, Y.; Barrelet, C. J.; Gradečak, S.; Xiang, J.; Timko B. P.; Lieber, C. M. Imaging and analysis of nanowires. Microscop. Res. Tech. 2004, 64, 373-389.

61. Qian, F.; Li, Y.; Gradečak, S.; Wang, D.; Barrelet, C. J.; Lieber, C. M. Gallium nitride-based nanowire radial heterostructures for nanophotonics. Nano Lett. 2004, 4, 1975-1979.

62. Zheng, G.; Lu, W.; Jin S.; Lieber, C. M. Synthesis and fabrication of high-performance n-type silicon nanowire transistors. Adv. Mater. 2004, 16, 1890-1893.

63. Lu, W.; Xiang, J.; Timko B. P.; Wu, Y.; Lieber, C. M. One-dimensional hole gas in germanium/silicon nanowire heterostructures. Proc. Natl. Acad. Sci. USA 2005, 102, 1004610051.

64. Radovanovic, P. V.; Barrelet, C. J.; Gradečak, S.; Qian, F.; Lieber, C. M. General synthesis of manganese-doped II-VI and III-V semiconductor nanowires. Nano Lett. 2005, 5, 1407-1411.

65. Qian, F.; Gradečak, S.; Li, Y.; Wen, C.; Lieber, C. M. Core/multishell nanowire heterostructures as multicolor, high-efficiency light-emitting diodes. Nano Lett. 2005, 5, 2287-2291.

66. Yang, C.; Zhong, Z.; Lieber, C. M. Encoding electronic properties by synthesis of axial modulation doped silicon nanowires. Science 2005, 310, 1304-1307.

67. Xiang, J.; Lu, W.; Hu, Y.; Wu, Y.; Yan, H.; Lieber, C. M. Ge/Si nanowire heterostructures as high-performance field-effect transistors. Nature 2006, 441, 489-493.

68. Li, Y.; Xiang, J.; Qian, F.; Gradečak, S.; Wu, Y.; Yan, H.; Blom, D. A.; Lieber, C. M. Dopantfree GaN/AlN/AlGaN radial nanowire heterostructures as high electron mobility transistors. Nano Lett. 2006, 6, 1468-1473.

69. Li, Y.; Qian, F.; Xiang, J.; Lieber, C. M. Nanowire electronic and optoelectronic devices. Materials Today 2006, 9, 18-27.

70. Agarwal, R.; Lieber, C. M. Semiconductor nanowires: optics and optoelectronics. Appl. Phys. A: Mater. Sci. Proc. 2006, 85, 209-215.

71. Lu, W.; Lieber, C. M. Semiconductor nanowires. J. Phys. D: Appl. Phys. 2006, 39, R387-R406.

72. Yang, C.; Barrelet, C. J.; Capasso, F.; Lieber, C. M. Single p-type/intrinsic/n-type silicon nanowires as nanoscale avalanche photodetectors. Nano Lett. 2006, 6, 2929-2934. 
73. Lieber, C. M.; Wang, Z. L.; Functional nanowires. MRS Bull. 2007, 32, 99-104.

74. Jiang, X.; Xiong, Q.; Nam, S.; Qian, F.; Li, Y.; Lieber, C. M. InAs/InP radial nanowire heterostructures as high electron mobility devices. Nano Lett. 2007, 7, 3214-3218.

75. Tian, B.; Zheng, X.; Kempa, T. J.; Fang, Y.; Yu, N.; Yu, G.; Huang, J.; Lieber, C. M. Coaxial silicon nanowires as solar cells and nanoelectronic power sources. Nature 2007, 449, 885-890.

76. Dong, Y.; Yu, G.; McAlpine, M. C.; Lu, W.; Lieber, C. M. Si/a-Si Core/Shell Nanowires as Nonvolatile Crossbar Switches. Nano Lett. 2008, 8, 386-391.

77. Park, W. I.; Zheng, G.; Xiang, J.; Tian, B.; Lieber, C. M. Controlled synthesis of millimeter-long silicon nanowires with uniform electronic properties. Nano Lett. 2008, 8, 3004-3009.

78. Qian, F.; Li, Y.; Gradečak, S.; Park, H.-G.; Dong, Y.; Ding, Y.; Wang Z. L.; Lieber, C. M. Multi-quantum-well nanowire heterostructures for wavelength-controlled lasers. Nature Mater. 2008, 7, 701-706.

79. Kempa, T. J.; Tian, B.; Kim, D. R.; Hu, J.; Zheng, X.; Lieber, C.M. Single and tandem axial p-in nanowire photovoltaic devices. Nano Lett. 2008, 8, 3456-3460.

80. Dong, Y.; Tian, B.; Kempa, T.; Lieber, C.M. Coaxial group III-nitride nanowire photovoltaics. Nano Lett 2009, 9, 2183-2187.

81. Zwanenburg, F. A.; Loon, A. A. van; Steele, G. A.; Rijmenam, C. E. W. M. van; Balder, T.; Kouwenhoven, L. P.; Fang, Y.; Lieber, C. M. Ultra-small silicon quantum dots. J. Appl. Phys. 2009, 105, 124314-1.

82. Xie, P.; Hu, Y.; Fang, Y.; Huang, J.; Lieber, C. M. Diameter-dependent dopant location in silicon and germanium nanowires. Proc. Natl. Acad. Sci. USA 2009, 106, 15254-15258.

83. Tian, B.; Xie, P.; Kempa, T. J.; Bell, D. C.; Lieber, C. M. Single crystalline kinked semiconductor nanowire superstructures. Nature Nanotechnol. 2009, 4, 824-829.

84. Tian, B.; Cohen-Karni, T.; Qing, Q.; Duan, X.; Xie, P.; Lieber, C. M. Three-dimensional, flexible nanoscale field effect transistors as localized bioprobes. Science 2010, 329, 831-834.

85. Jiang, X.; Tian, B.; Xiang, J.; Qian, F.; Zheng, G.; Wang, H.; Mai, L.; Lieber, C. M. Rational growth of branched nanowire heterostructures with synthetically encoded properties and function. Proc. Natl. Acad. Sci. USA 2011, 108, 12212-12216.

86. Lieber, C. M. Semiconductor nanowires: A platform for nanoscience and nanotechnology. MRS Bull. 2011, 36, 1052-1063.

87. Kempa, T. J.; Cahoon, J. F.; Kim, S.-K.; Day, R. W.; Bell, D. C.; Park, H.-G.; Lieber, C. M. Coaxial multishell nanowires with high-quality electronic interfaces and tunable optical cavities for ultrathin photovoltaics. Proc. Natl. Acad. Sci. USA 2012, 109, 1407-1412. 
88. Jiang, Z.; Qing, Q.; Xie, P.; Gao, R.; Lieber, C. M. Kinked p-n junction nanowire probes for high spatial resolution sensing and intracellular recording. Nano Lett. 2012, 12, 1711-1716.

89. Cohen-Karni, T.; Casanova, D.; Cahoon, J.; Qing, Q.; Bell, D.; Lieber, C. M. Syntheticallyencoded ultrashort-channel nanowire transistors for fast, point-like cellular signal detection. Nano Lett. 2012, 12, 2639-2644.

90. Xu, L.; Jiang, Z.; Qing, Q.; Mai, L.; Zhang, Q.; Lieber, C. M. Design and synthesis of diverse functional kinked nanowire structures for nanoelectronic bioprobes. Nano Lett. 2013, 13, 746751.

91. Kempa, T., Kim, S-K.; Day, R.; Park, H-G.; Nocera, D.; Lieber, C. M. Facet-selective growth on nanowires yields multi-component nanostructures and photonic devices. J. Am. Chem. Soc. 2013, $135,18354-18357$.

92. Duan, X.; Huang, Y.; Cui, Y.; Wang, J.; Lieber, C. M. Indium phosphide nanowires as building blocks for nanoscale electronic and optoelectronic devices. Nature 2001, 409, 66-69.

93. Huang, Y.; Duan, X.; Wei, Q.; Lieber, C. M. Directed assembly of one-dimensional nanostructures into functional networks. Science 2001, 291, 630-633.

94. Cui, Y.; Lieber, C. M. Functional nanoscale electronic devices assembled using silicon nanowire building blocks. Science 2001, 291, 851-853.

95. Lieber, C. M. The incredible shrinking circuit. Sci. Am. 2001, 285, 50-56.

96. Huang, Y.; Duan, X.; Cui, Y.; Lauhon, L.; Kim, K.; Lieber, C. M. Logic gates and computation from assembled nanowire building blocks. Science 2001, 294, 1313-1317.

97. Lieber, C. M. Nanoscience and nanotechnology: Building a big future from small things; Update. New York Academy of Sciences: New York, 2002; pp 6-9.

98. Duan, X.; Huang, Y.; Lieber, C. M. Nanowire nanocircuits. In McGraw-Hill Yearbook of Science and Technology. Licker, M. D.et al. Eds.; McGraw-Hill: 2003; pp 272-276.

99. Lieber, C. M. Nanoscale science and technology: Building a big future from small things. MRS Bull. 2003, 28, 486-491.

100. Whang, D.; Jin, S.; Wu Y.; Lieber, C. M. Large-scale hierarchical organization of nanowire arrays for integrated nanosystems. Nano Lett. 2003, 3, 1255-1259.

101. McAlpine, M. C.; Friedman, R. S.; Jin, S.; Lin, K.; Wang, W. U.; Lieber, C. M. Highperformance nanowire electronics and photonics on glass and plastic substrates. Nano Lett. 2003, $3,1531-1535$.

102. Zhong, Z.; Wang, D.; Cui, Y.; Bockrath, M. W.; Lieber, C. M. Nanowire crossbar arrays as address decoders for integrated nanosystems. Science 2003, 302, 1377-1379. 
103. Jin, S.; Whang, D.; McAlpine, M. C.; Friedman, R. S.; Wu, Y.; Lieber, C. M. Scalable interconnection and integration of nanowire devices without registration. Nano Lett. 2004, 4, 915-919.

104. Huang, Y.; Duan, X.; Lieber, C. M. Nanowires for integrated multicolor nanophotonics. Small 2005, 1, 142-147.

105. Agarwal, R.; Ladavac, K.; Roichman, Y.; Yu, G.; Lieber, C. M.; Grier, D. G. Manipulation and assembly of nanowires with holographic optical traps. Opt. Express 2005, 13, 8906-8912.

106. Javey, A.; Nam, S.; Friedman, R. S.; Yan, H.; Lieber, C. M. Layer-by-layer assembly of nanowires for three-dimensional, multifunctional electronics. Nano Lett. 2007, 7, 773-777.

107. Lu, W.; Lieber, C. M. Nanoelectronics from the bottom up. Nature Mater. 2007, 6, 841-850.

108. Yan, H.; Choe, H. S.; Nam, S. W.; Hu, Y.; Das, S.; Klemic, J. F.; Ellenbogen, J. C.; Lieber, C. M. Programmable nanowire circuits for nanoprocessors. Nature 2011, 470, 240-244.

109. Yao, J.; Yan, H.; Lieber, C. M. A nanoscale combing technique for the large-scale assembly of highly aligned nanowires. Nature Nanotechnol. 2013, 8, 329-335.

110. Yao. J.; Yan, H.; Das, S.; Klemic, J.; Ellenbogen, J.; Lieber, C. M. Nanowire nanocomputer as a finite-state machine. Proc. Natl. Acad. Sci. USA 2014, 111, 2431-2435.

111. Huang, Y.; Duan, X.; Cui, Y.; Lieber, C. M. Gallium nitride nanowire nanodevices. Nano Lett. 2002, 2, 101-104.

112. Duan, X.; Huang, Y.; Cui, Y.; Lieber, C. M. Nonvolatile memory and programmable logic from molecule-gated nanowires. Nano Lett. 2002, 2, 487-490.

113. Cui, Y.; Zhong, Z.; Wang, D.; Wang, W. U.; Lieber, C. M. High performance silicon nanowire field effect transistors. Nano Lett. 2003, 3, 149-152.

114. Friedman, R. S.; McAlpine, M. C.; Ricketts, D. S.; Ham, D.; Lieber, C. M. High-speed integrated nanowire circuits. Nature 2005, 434, 1085.

115. McAlpine, M. C.; Friedman, R. S.; Lieber, C. M. High-performance nanowire electronics and photonics and nanoscale patterning on flexible plastic substrates. Proc. IEEE 2005, 93, 13571363.

116. Hu, Y.; Xiang, J.; Liang, G.; Yan, H.; Lieber, C. M. Sub-100 nanometer channel length Ge/Si nanowire transistors with potential for $2 \mathrm{THz}$ switching speed. Nano Lett. 2008, 8, 925-930.

117. Lu, W.; Xie, P.; Lieber, C. M. Nanowire transistor performance limits and applications. IEEE Trans. Electron Dev. 2008, 55, 2859-2876.

118. Nam, S. W.; Jiang, X.; Xiong, Q.; Ham, D.; Lieber, C. M. Vertically integrated, threedimensional nanowire complementary metal-oxide-semiconductor circuits. Proc. Natl. Acad. Sci. USA, 2009, 106, 21035-21038. 
119. Zhong, Z.; Fang, Y.; Lu, W.; Lieber, C. M. Coherent single charge transport in molecular-scale silicon nanowires. Nano Lett. 2005, 5, 1143-1146.

120. Xiang, J.; Vidan, A.; Tinkham, M.; Westervelt, R. M.; Lieber, C. M. Ge/Si nanowire mesoscopic Josephson junctions. Nature Nanotechnol. 2006, 1, 208-213.

121. Hu, Y.; Churchill, H.O.H.; Reilly, D. J.; Xiang, J.; Lieber, C. M.; Marcus, C. M. A Ge/Si heterostructure nanowire-based double quantum dot with integrated charge sensor. Nat. Nanotechnol. 2007, 2, 622-625.

122. Roddaro, S.; Fuhrer, A.; Brusheim, P.; Fasth, C.; Xu, H. Q.; Samuelson, L.; Xiang, J.; Lieber, C. M. Spin states of holes in Ge/Si nanowire quantum dots. Phys. Rev. Lett. 2008, 101, 186802-1 -4.

123. Zwanenburg, F. A.; Rijmenam, C.E.W.M. van; Fang, Y.; Lieber, C. M.; Kouwenhoven, L. P.; Spin states of the first four holes in a silicon nanowire quantum dot. Nano Lett. 2009, 9, 10711079.

124. Lee, E. J. H.; Jiang, X.; Aguado, R.; Katsaros, G.; Lieber, C. M.; De Franceschi, S. Zero-bias anomaly in a nanowire quantum dot coupled to superconductors. Phys. Rev. Lett. 2012, 109, 186802-1-5.

125. Lee, E.; Jiang, X.; Houzet, M.; Aguado, R.; Lieber, C. M.; De Franceschi, S. Spin-resolved Andreev levels and parity crossings in hybrid superconductor-semiconductor nanostructures. Nature Nanotechnol. 2014, 9, 79-84.

126. Higginbotham, A.; Larsen, T.; Yao, J.; Yan, H.; Lieber, C. M.; Marcus, C.; Kuemmeth, F. Hole spin coherence in a Ge/Si heterostructure nanowire. Nano Lett. 2014, 14, 3582-3586.

127. Higginbotham, A.; Kuemmeth, F.; Larsen, T.; Yao, J.; Yan, H.; Lieber, C. M.; Marcus, C. Antilocalization of coulomb blockade in Ge/Si nanowire. Phys. Rev. Lett. 2014, 112, 216806.

128. Wang, J.; Gudiksen, M. S.; Duan, X.; Cui, Y.; Lieber, C. M. Highly polarized photoluminescence and photodetection from single indium phosphide nanowires. Science 2001, 293, 1455-1457.

129. Duan, X.; Huang, Y.; Agarwal, R.; Lieber, C. M. Single-nanowire electrically driven lasers. Nature 2003, 421, 241-245.

130. Barrelet, C. J.; Greytak, A. B.; Lieber, C. M. Nanowire photonic circuit elements. Nano Lett. 2004, 4, 1981-1985.

131. Agarwal, R.; Barrelet, C. J.; Lieber, C. M. Lasing in single cadmium sulfide nanowire optical cavities. Nano Lett. 2005, 5, 917-920.

132. Greytak, A. B.; Barrelet, C. J.; Li, Y.; Lieber, C. M. Semiconductor nanowire laser and nanowire waveguide electro-optic modulators. Appl. Phys. Lett. 2005, 87, 151103-1 - 3. 
133. Gradečak, S.; Qian, F.; Li, Y.; Park, H.-G.; Lieber, C. M. GaN nanowire lasers with low lasing thresholds. Appl. Phys. Lett. 2005, 87, 173111-1 -3.

134. Barrelet, C. J.; Bao, J.; Loncar, M.; Park, H.-G.; Capasso, F.; Lieber, C. M. Hybrid singlenanowire photonic crystal and microresonator structures. Nano Lett. 2006, 6, 11-15.

135. Hayden, O.; Agarwal, R.; Lieber, C. M. Nanoscale avalanche photodiodes for highly-sensitive and spatially-resolved photon detection. Nature Mater. 2006, 5, 352-356.

136. Park, H.-G.; Barrelet, C. J.; Wu, Y.; Tian, B.; Qian, F.; Lieber, C. M. A wavelength-selective photonic-crystal waveguide coupled to a nanowire light source. Nature Photon. 2008, 2, 622626.

137. Zhang, Q.; Li, G.; Liu, X.; Qian, F.; Li, Y.; Sum, T. C.; Lieber, C. M.; Xiong, Q. A room temperature low-threshold ultraviolet plasmonic nanolaser. Nature Comm. 2014, 5, 5953.

138. Tian, B.; Kempa, T. J.; Lieber, C. M. Single nanowire photovoltaics. Chem. Soc. Rev. 2009, 38, 16-24.

139. Kim, S. K.; Day, R. W.; Cahoon, J.; Kempa, T.; Song, K.; Park, H.-G.; Lieber, C. M. Tuning light absorption in core/shell silicon nanowire photovoltaic devices through morphological design. Nano Lett. 2012, 12, 4971-4976.

140. Kempa, T.; Day, R.; Kim, S.; Park, H.; Lieber, C. M. Semiconductor nanowires: A platform for exploring limits and concepts for nano-enabled solar cells. Energy Environ. Sci. 2013, 6, 719733.

141. Chan, C. K.; Peng, H.; Liu, G.; McIlwrath, K.; Zhang, X. F.; Huggins, R. A.; Cui, Y. Highperformance lithium battery anodes using silicon nanowires. Nature Nanotechnol. 2008, 3, 3135.

142. Yang, P.; Tarascon, J. M. Towards systems materials engineering. Nature Mater. 2012, 11, 560563.

143. Mai, L.; Tian, X.; Xu, X.; Chang, L.; Xu, L. Nanowire electrodes for electrochemical energy storage devices. Chem. Rev. 2014, DOI: 10.1021/cr500177a..

144. Cui, Y.; Wei, Q.; Park, H.; Lieber, C. M. Nanowire nanosensors for highly sensitive and selective detection of biological and chemical species. Science 2001, 293, 1289-1292.

145. Hahm, J.; Lieber, C. M. Direct ultrasensitive electrical detection of DNA and DNA sequence variations using nanowire nanosensors. Nano Lett. 2004, 4, 51-54.

146. Patolsky, F.; Zheng, G.; Hayden, O.; Lakadamyali, M.; Zhuang, X.; Lieber, C. M. Electrical detection of single viruses. Proc. Natl. Acad. Sci. USA 2004, 101, 14017-14022.

147. Wang, W. U.; Chen, C.; Lin, K.; Fang, Y.; Lieber, C. M. Label-free detection of small-moleculeprotein interactions by using nanowire nanosensors. Proc. Natl. Acad. Sci. USA 2005, 102, 32083212. 
148. Zheng, G.; Patolsky, F.; Cui, Y.; Wang, W. U.; Lieber, C. M. Multiplexed electrical detection of cancer markers with nanowire sensor arrays. Nat. Biotechnol. 2005, 23, 1294-1301.

149. Patolsky, F.; Zheng, G.; Lieber, C. M. Nanowire sensors for medicine and the life sciences. Nanomedicine 2006, 1, 51-65.

150. Patolsky, F.; Timko, B. P.; Yu, G.; Fang, Y.; Greytak, A. B.; Zheng, G.; Lieber, C. M. Detection, stimulation, and inhibition of neuronal signals with high-density nanowire transistor arrays. Science 2006, 313, 1100-1104.

151. Patolsky, F.; Zheng, G.; Lieber, C. M. Fabrication of silicon nanowire devices for ultrasensitive, label-free, real-time detection of biological and chemical species. Nat. Protocols 2006, 1, 17111724.

152. Timko, B. P.; Cohen-Karni, T.; Yu, G.; Qing, Q.; Tian, B.; Lieber, C. M. Electrical recording from hearts with flexible nanowire device arrays. Nano Lett. 2009, 9, 914-918.

153. Cohen-Karni, T.; Timko, B. P.; Weiss, L. E.; Lieber, C. M. Flexible electrical recording from cells using nanowire transistor arrays. Proc. Natl. Acad. Sci. USA 2009, 106, 7309-7313.

154. Gao, X. P.; Zheng, G.; Lieber, C. M. Subthreshold regime has the optimal sensitivity for nanowire FET biosensors. Nano Lett. 2010, 10, 547-552.

155. Qing, Q.; Pal, S. K.; Tian, B.; Duan, X.; Timko, B. P.; Cohen-Karni, T.; Murthy, V. N.; Lieber, C. M. Nanowire transistor arrays for mapping neural circuits in acute brain slices. Proc. Natl. Acad. Sci. USA 2010, 107, 1882-1887.

156. Cohen-Karni, T.; Qing, Q.; Li, Q.; Fang, Y.; Lieber, C. M. Graphene and nanowire transistors for cellular interfaces and electrical recording. Nano Lett. 2010, 10, 1098-1102.

157. Timko, B. P.; Cohen-Karni, T.; Qing, Q.; Tian, B.; Lieber, C. M. Design and implementation of functional nanoelectronic interfaces with biomolecules, cells and tissue using nanowire device arrays. IEEE Trans. Nanotechnol. 2010, 9, 269-280.

158. Zheng, G.; Gao, X.; Lieber, C. M. Frequency domain detection of biomolecules using silicon nanowire biosensors. Nano Lett. 2010, 10, 3179-3183.

159. Xie, P.; Xiong, Q.; Fang, Y.; Qing, Q.; Lieber, C. M. Local electrical potential detection of DNA by nanowire-nanopore sensors. Nature Nanotechnol. 2012, 7, 119-125.

160. Duan, X.; Gao, R.; Xie, P.; Cohen-Karni, T.; Qing, Q.; Choe, H. S.; Tian, B.; Jiang, X.; Lieber, C. M Intracellular recordings of action potentials by an extracellular nanoscale field-effect transistor. Nature Nanotechnol. 2012, 7, 174-179.

161. Gao, R.; Strehle, S.; Tian, B.; Cohen-Karni, T.; Xie, P.; Duan, X.; Qing, Q.; Lieber, C. M. Outside looking in: Nanotube transistor intracellular sensors. Nano Lett. 2012, 12, 3329-3333. 
162. Tian, B.; Liu, J.; Dvir, T.; Jin, L.; Tsui, J. H.; Qing, Q.; Suo, Z.; Langer, R.; Kohane, D. S.; Lieber, C. M. Macroporous nanowire nanoelectronic scaffolds for synthetic tissues. Nature Mater. 2012, 11, 986-994.

163. Liu, J.; Xie, C.; Dai, X.; Jin, L.; Zhou, W.; Lieber, C. M. Multifunctional three-dimensional macroporous nanoelectronic networks for smart materials,Proc. Natl. Acad. Sci. USA. 2013, 110, 6694-6699.

164. Tian, B.; Lieber, C. M. Synthetic nanoelectronic probes for biological cells and tissues. Annu. Rev. Anal. Chem. 2013, 6, 31-51.

165. Duan, X.; Fu, T.-M.; Liu, J.; Lieber, C. M. Nanoelectronics-biology frontier: From nanoscopic probes for action potential recording in live cells to three-dimensional cyborg tissues. Nano Today 2013, 8, 351-373.

166. Qing, Q.; Jiang, Z.; Xu, L.; Gao, R.; Mai, L.; ; Lieber, C. M. Free-standing kinked nanowire transistor probes for targeted intracellular recording in three dimensions. Nature Nanotechnol. 2014, 9, 142-147.

167. Fu, T.-M.; Duan, X.; Jiang, Z.; Dai, X.; Xie, P.; Cheng, Z.; Lieber, C. M. Sub-10 nanometer intracellular bioelectronic probes from nanowire-nanotube heterostructures. Proc. Natl. Acad. Sci. USA 2014, 111, 1259-1264.

168. Zhou, W.; Dai, X.; Fu, T-M.; Xie, C.; Liu, J.; Lieber, C. M. Long term stability of nanowire nanoelectronics in physiological environments. Nano Lett. 2014, 14, 1614-1619.

169. Xie, C; Lin, Z.; Hanson, L.; Cui, Y.; Cui, B. Intracellular recording of action potentials by nanopillar electroporation. Nature Nanotechnol. 2012, 7, 185-190.

170. Robinson, J. T.; Jorgolli, M.; Shalek, A. K.; Yoon, M. H.; Gertner, R. S.; Park, H. Vertical nanowire electrode arrays as a scalable platform for intracellular interfacing to neuronal circuits. Nature Nanotechnol. 2012, 7, 180-184.

171. Shepherd, G. M. The Synaptic Organization of the Brain,5th Ed.; Oxford Univ Press, Inc.: New York, 2004.

172. Scanziani, M.; Hausser, M. Electrophysiology in the age of light. Nature 2009, 461, 930-939.

173. Seymour, J. P.; Kipke, D. R. Neural probe design for reduced tissue encapsulation in CNS. Biomaterials 2007, 28, 3594-3607.

174. Viventi, J.; Kim, D.-H.; Vigeland, L.; Frechette, E. S.; Blanco, J. A.; Kim, Y.-S.; Avrin, A. E.; Tiruvadi, V. R.; Hwang, S.-W.; Vanleer, A. C. et al. Flexible, foldable, actively multiplexed, high-density electrode array for mapping brain activity in vivo. Nature Neuroscience 2011, 14, 1599-1605.

175. Erickson, J.; Tooker, A.; Tai, Y. C.; Pine, J. Caged neuron MEA: a system for long-term investigation of culture neural network connectivity. J. Neurosceince methods 2008, 175, 1-16. 
176. Egert, U.; Heck, D.; Aertsen, A. 2-Dimensional monitoring of spiking networks in acute brain slices. Exp.Brain Res. 2002, 142, 268-274.

177. Wirth, C.; Lüscher, H. R.Spatiotemporal Evolution of Excitation and Inhibition in the Rat Barrel Cortex Investigated With Multielectrode Arrays. J. Neurophysiol. 2004, 91, 1635-1647.

178. Frey, U.; Egert, U.; Heer, F.; Hafizovic, S.; Hierlemann, A. Microelectronic system for highresolution mapping of extracellular electric fields applied to brain slices. Biosens. Bioelectron. 2009, 24, 2191-2198.

179. Stangl, C.; Fromherz, P. Neuronal field potential in acute hippocampus slice recorded with transistor and micropipette electrode. Eur. J. Neurosci. 2008, 27, 958-964.

180. Molleman, A. Patch Clamping: An Introductory Guide to Patch Clamp Electrophysiology; John Wiley \& Sons, Ltd.: Chichester, West Sussex, England, 2003.

181. Davie, J. T.; Kole, M. H. P.; Letzkus, J. J.; Rancz, E. A.; Spruston, N.; Stuart, G. J.; Hausser, M. Dendritic patch-clamp recording. Nat. Protoc. 2006, 1, 1235 -1247.

182. Duan, X.; Lieber, C. M. Nanoelectronics Meets Biology: From New Nanoscale Devices for Live-Cell Recording to 3D Innervated Tissues. Chem. Asian J. 2013, 8, 2304-2314.

183. Bers, D. M. Cardiac excitation-contraction coupling. Nature 2002, 415, 198 - 205.

184. Koch, C.; Reid, R. C. Neuroscience: Observatories of the mind. Nature 2012, 483, 397 -398.

185. Dvir, T.; Timko, B. P.; Kohane, D. S.; Langer, R. Nanotechnological strategies for engineering complex tissues. Nat. Nanotechnol. 2011, 6, 13-22.

186. Dvir, T.; Timko, B. P.; Brigham, M. D.; Naik, S. R.; Karajanagi, S. S.; Levy, O. Nanowired three-dimensional cardiac patches. Nat Nanotechnol. 2011, 6, 720-725.

187. Kim, D. H.; Lu, N. S.; Ma, R.; Kim, Y. S.; Kim, R. H.; Wang, S. D.; Wu, J.; Won, S. M.; Tao, H.; Islam, A. et al. Epidermal Electronics. Science, 2011, 333, 838-843. 


\section{Figure Captions}

Figure 1. Functional nanowire building blocks through design and rational synthesis. Parent nanowire structure consists of uniform composition and doping (green) and diameter; the nanocluster catalyst (golden) is highlighted at the left tip of the structure. (clockwise from lower left) Axial nanowire with composition and/or doping (indicated by different colors) modulated during elongation of the structure; core/shell or coaxial nanowire with composition and/or doping (indicated by different colors) modulated by sequential two-dimensional shell growth following axial elongation; branched or tree-like nanowire with unique composition and/or doping branches are elaborated by sequential nanocluster-catalyzed growth; and a kinked nanowire with structurally coherent "kinks" introduced in a controlled manner during axial elongation. Reproduced with permission from ref. 86. Copyright Materials Research Society, 2011.

Figure 2. Nanowire building blocks for science and technology applications. Functional nanowire building blocks have made a substantial impact and/or have the potential to be transformative on a widerange of science and technology areas, including those indicated in the blue ellipses.

Figure 3. Schematics of interfacing nano-bioelectronics with the brain. (left) Illustration of the brain with superimposed electrophysiological recording of brain activity. (right) Higher-resolution depiction of a nanoelectronic network merged with a neural network after implantation of the nanoelectronic network within the brain.

Figure 4: Extracellular recording with nanoscale devices. (A) Extracellular action potential recording from cultured neurons. Left: optical image of a cortical neuron interfaced to three of the four SiNW FETs in an array; scale bar is $20 \mu \mathrm{m}$; right: trace of intracellular current stimulation (IC Stim) and resulting electrical responses from the four SiNW FETs. Reproduced with permission from ref. 147150. Copyright American Association for the Advancement of Science, 2006. (B) Extracellular field and action potential recording from acute brain slices with an array of SiNW FETs. Left: optical image of an acute slice over a $4 \times 4$ NW FET array; the relative position on the brain slice of the eight devices used for recording are shown with respective numbering on the $4 \times 4$ grid. Crosses along the LOT fiber region of the slice mark the stimulation spots a-h. Scale bar is $100 \mu \mathrm{m}$; right: Maps of the relative signal intensity or neuronal activity for devices 1-8. Reproduced with permission from ref. 152155. Copyright National Academy of Sciences, 2010.

Figure 5: Intracellular recording with nanoscale devices. (A) Kinked nanowire intracellular probe. (top) SEM image of a doubly kinked nanowire with a cis configuration of two kinks; scale bar, $200 \mathrm{~nm}$. Inset: schematic of kinked nanowire probe with active FET region (pink) encoded by dopant level modulation during synthesis. (Bottom) A 3D free-standing kinked nanowire FET probe fabricated on a substrate. The yellow arrow and pink star mark the nanoscale FET and SU-8, respectively. The 3D presentation of the nanowire device was achieved by introducing stress into the metal interconnects during fabrication, where the stress is subsequently relieved by 'bending up' the device. Scale bars, $5 \mu \mathrm{m}$; (B) SEM image of an ultrasmall BIT-FET with nanotube ID $\sim 8 \mathrm{~nm}$, and $\mathrm{SiO}_{2}$ wall thickness $\sim 10 \mathrm{~nm}$. Inset: zoom of the 
tip of the ultrasmall $\mathrm{SiO}_{2}$ nanotube; scale bars, $100 \mathrm{~nm}$. (C) false-color microscopic image of a HL-1 cell penetrated by a kinked nanowire FET probe. Scale bars, $5 \mu \mathrm{m}$ (D) Transition from extracellular to intracellular recordings during internalization of a kinked nanowire FET probe into a beating cardiomyocyte cell. Green and pink stars denote the peak positions of intracellular and extracellular signal components, respectively. Reproduced with permission from ref. 84, 164167. Copyright American Association for the Advancement of Science, 2010. National Academy of Sciences, 2014.

Figure 6: Innervating tissue in 3D with nanoelectronic networks. (A) Schematic illustrating conceptual steps for creating artificial tissues merged with addressable nanoelectronic elements in 3D. (B) 3D reconstructed confocal fluorescence micrograph of a nanoES. Solid and dashed open magenta squares indicate two kinked SiNW FET devices located on different planes; scale bar, $20 \mu \mathrm{m}$. (C) 3D reconstructed confocal images of rat hippocampal neurons after two-week culture on a nanoES similar to that shown in (B). Dimensions : $\mathrm{x}=317, \mathrm{y}=317, \mathrm{z}=100 \mu \mathrm{m}$. (D) Multiplexed electrical recording of extracellular action potentials from four SiNW FETs at different depth in a nanoES/cardiac tissue hybrid. Data are conductance versus time traces of the propagating field potential recorded at each SiNW FET while cells within the 3D tissue beat. Reproduced with permission from ref. 159162. Copyright 2012 Nature Publishing Group, 2012.

Figure 7. Conceptual steps for realizing minimally-invasive implantation of a nanoelectronic network into the brain. (A) Fabrication of a flexible, free-standing macroporous nanoelectronic network. The green dots indicate positions of the nanoelectronic devices, and the red lines correspond to both encapsulated electronic interconnects and structural elements. (B) The highly flexible nanoelectronic network is delivered into the brain by either injecting through a needle inserted into the brain (shown) or inserting supported on a removable or biodegradable rigid support probe. (C) Depiction of the nanoelectronic network merged with a brain neural network after implantation in a minimally-invasive manner. The color designations for the nanoelectronic network are the same as in (A). 

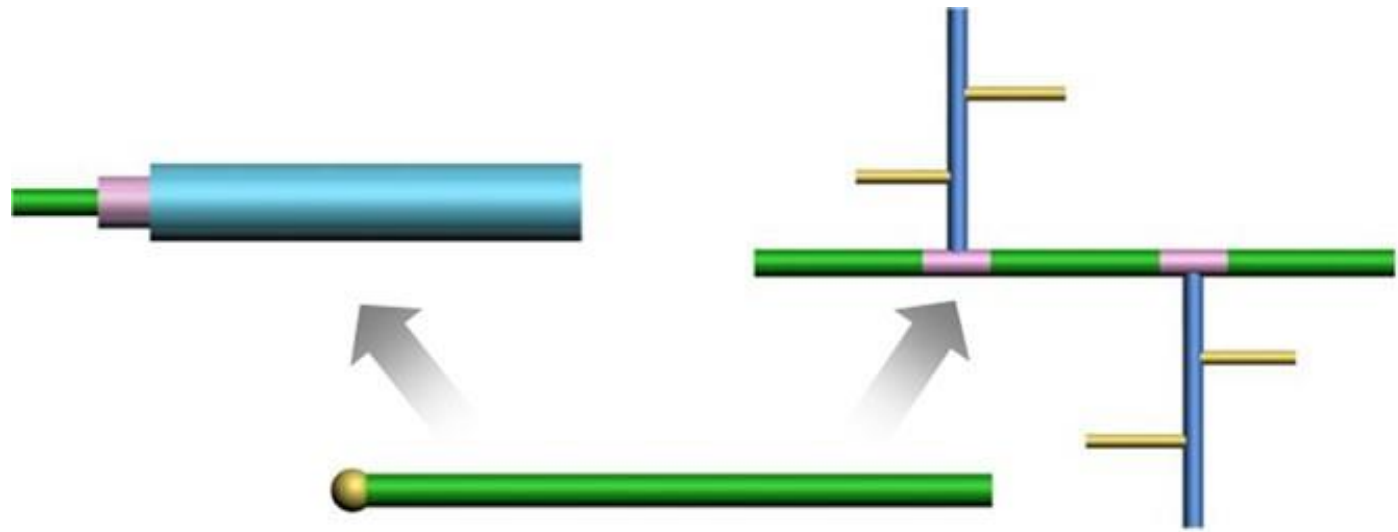

Figure 1

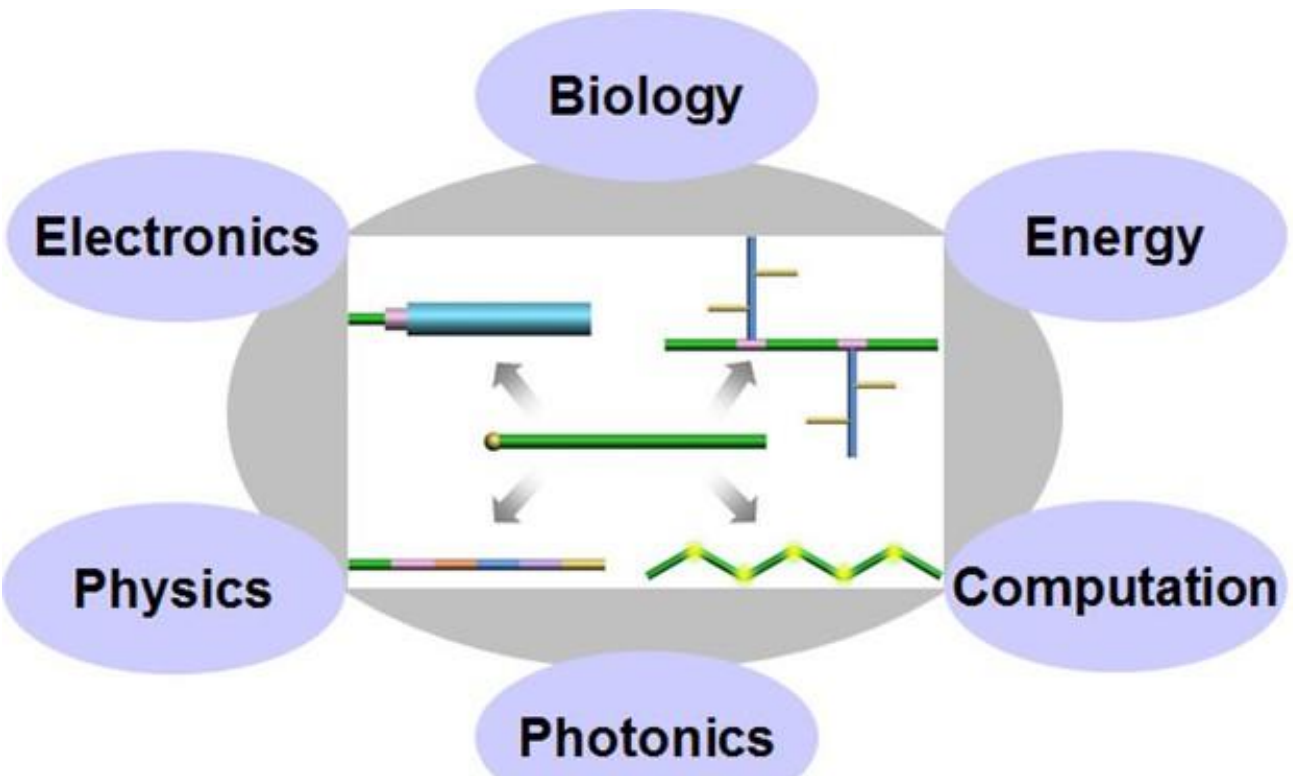

Figure 2 

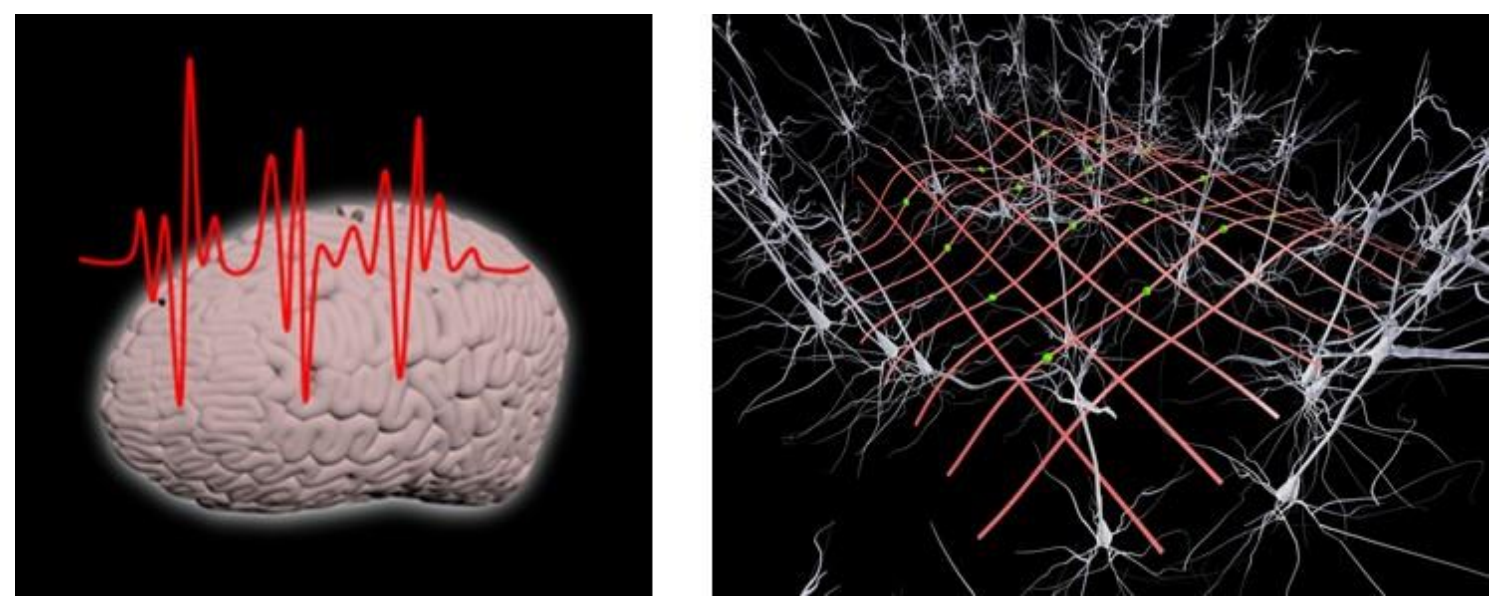

Figure 3
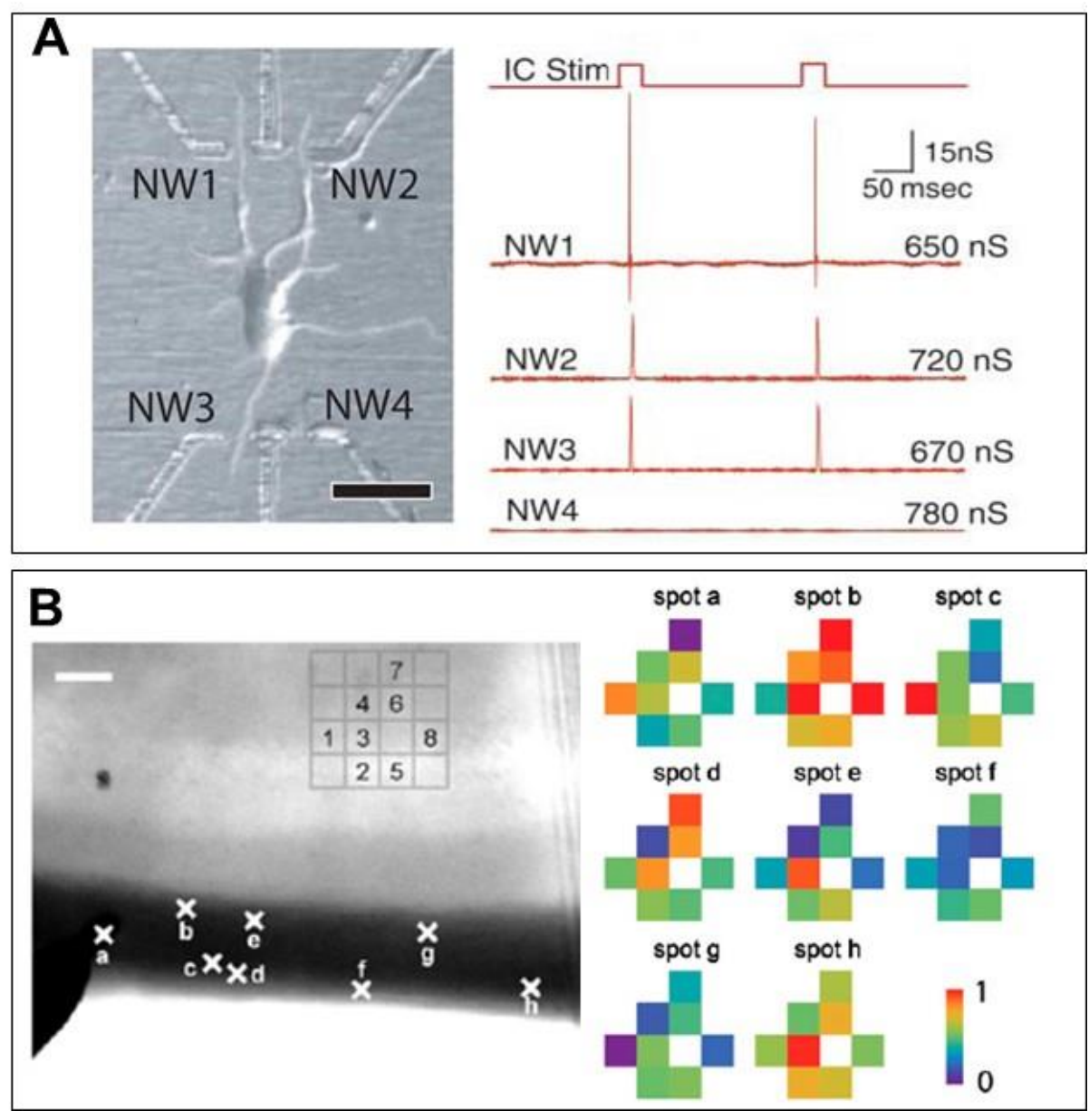

Figure 4 

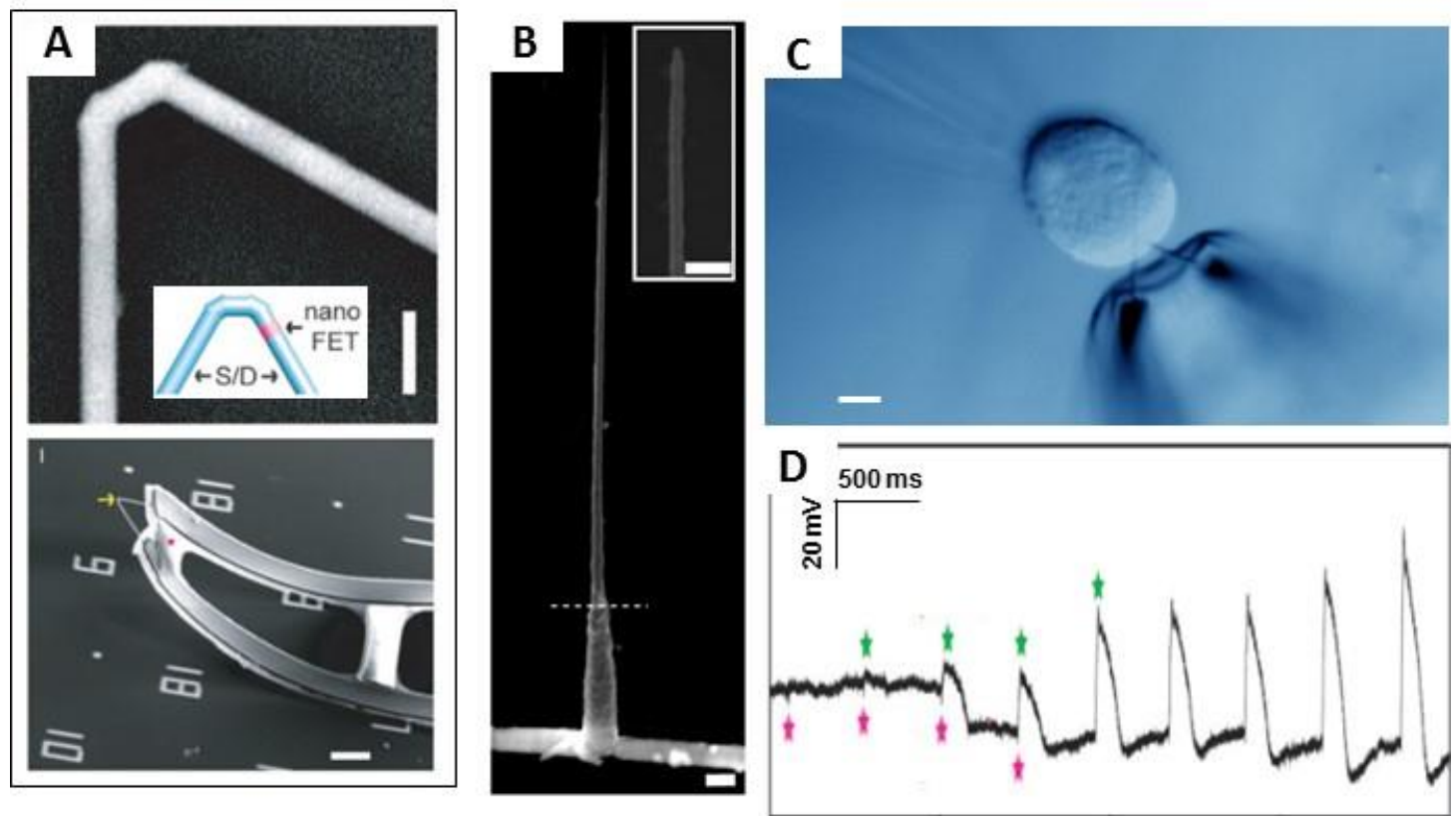

Figure 5

A
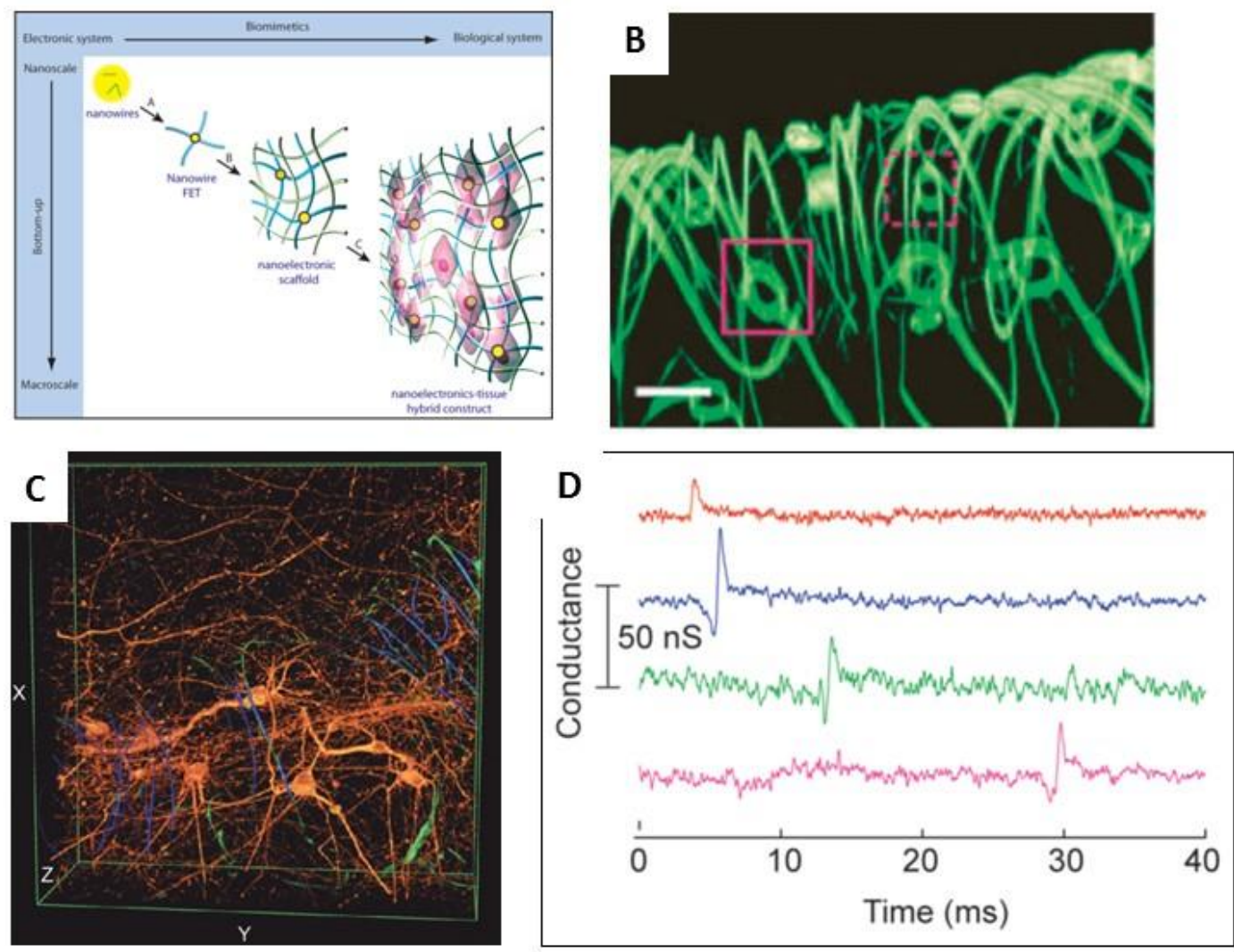

Figure 6 

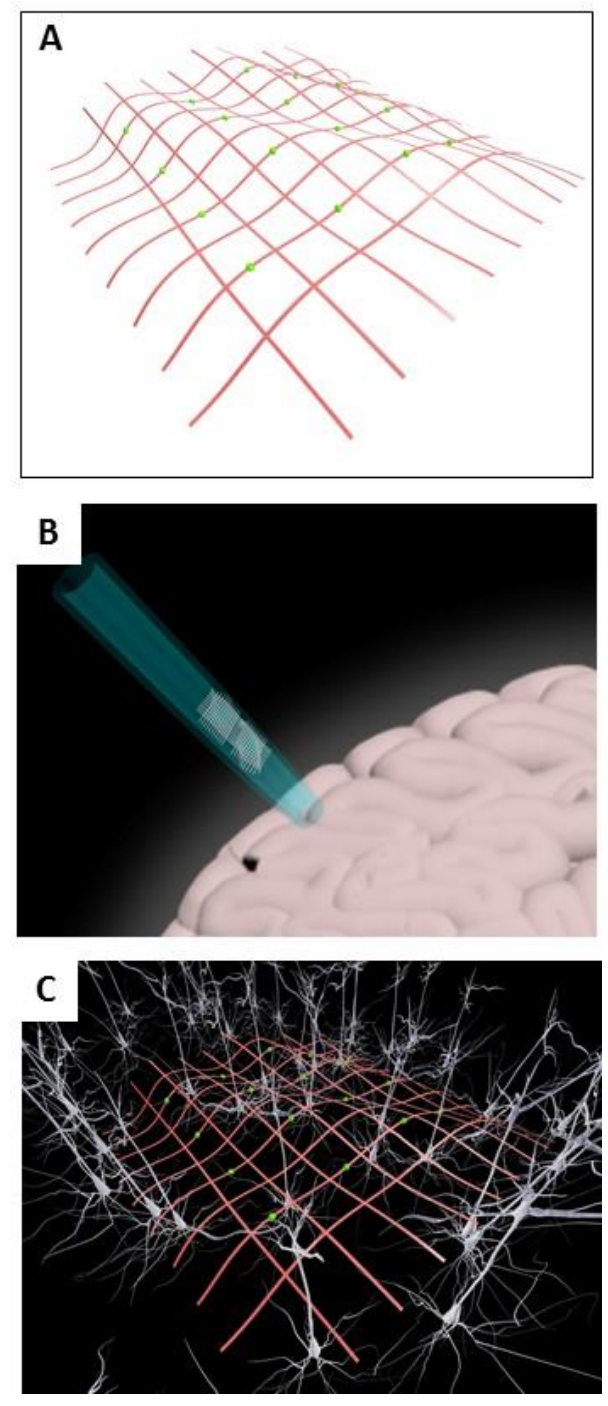

Figure 7 
Addendum: Table-1. Chinese coworkers trained in Lieber Research Group. Chinese graduate student, postdoctoral and visitor coworkers in chronological order. Undergraduate institutions in China are noted for graduate students and postdoctoral fellows, and current positions for all former coworkers are listed when available.

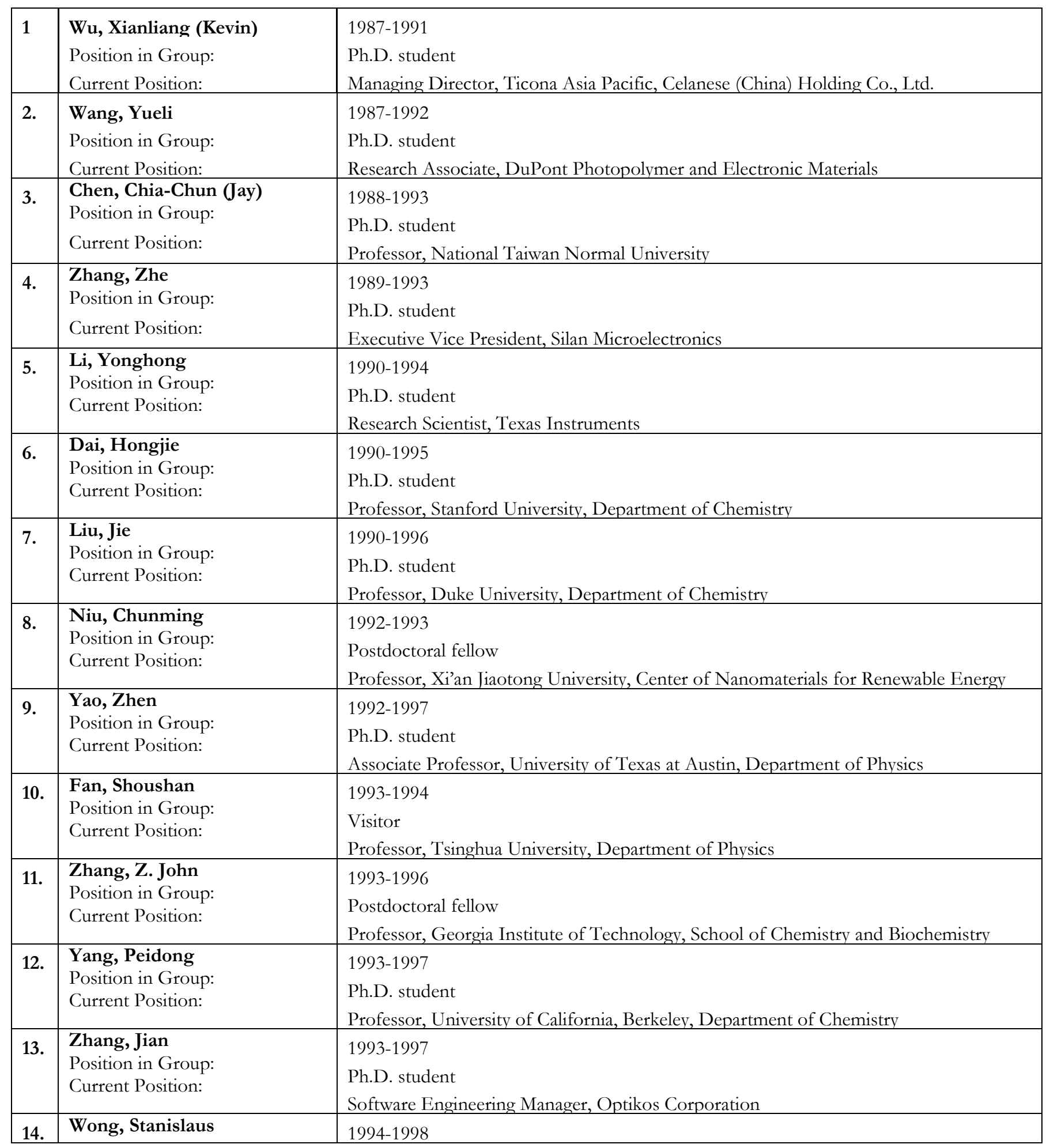




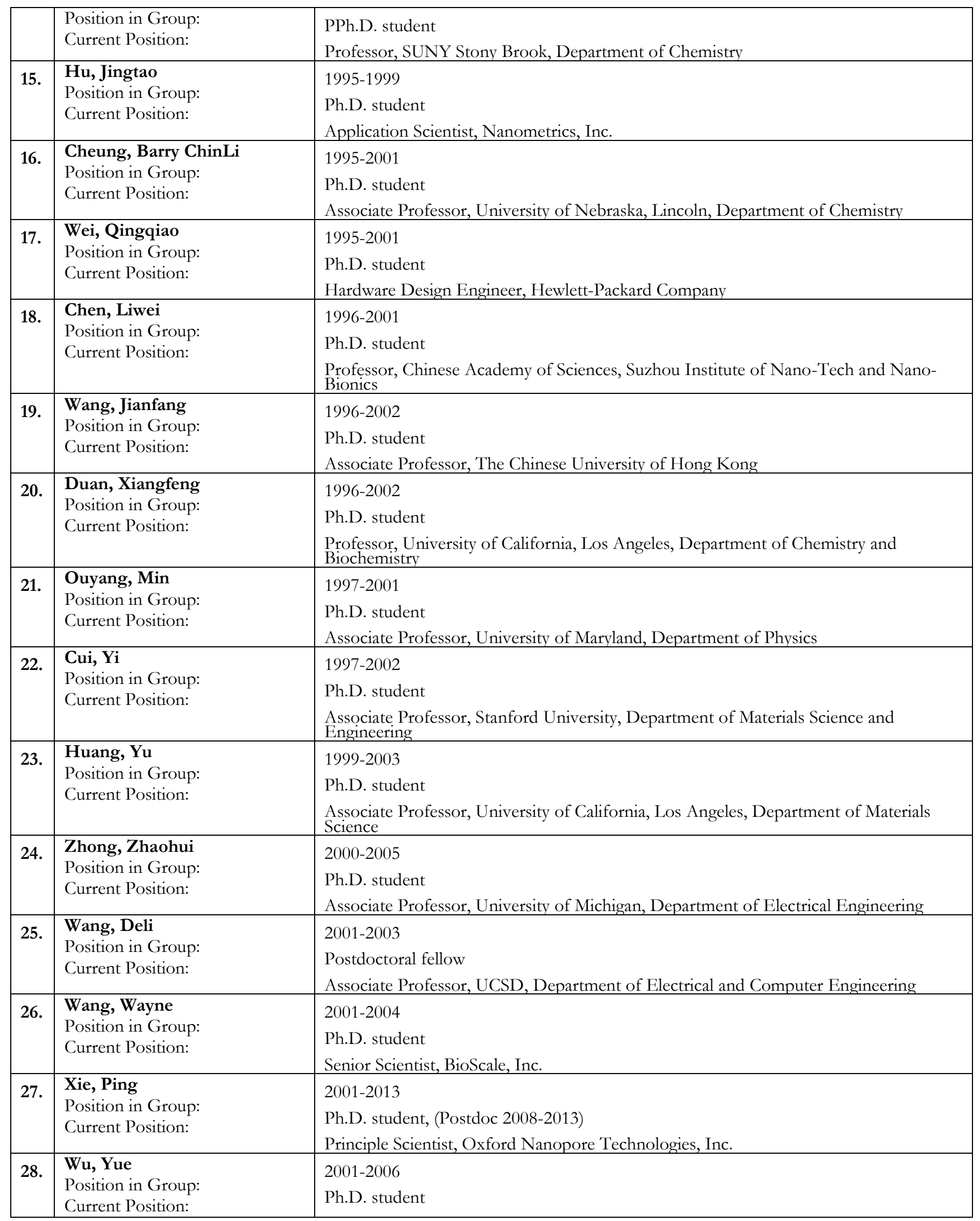




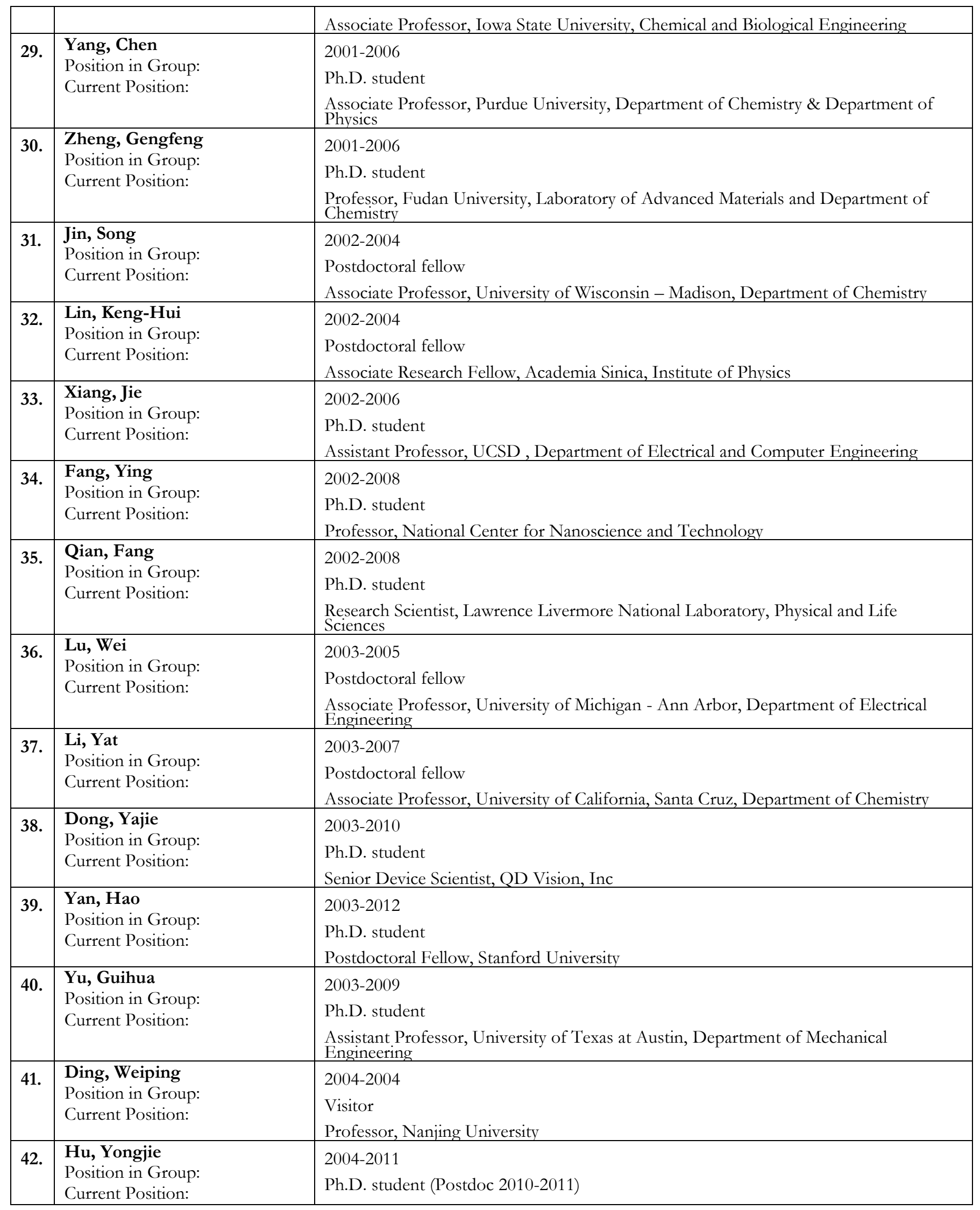




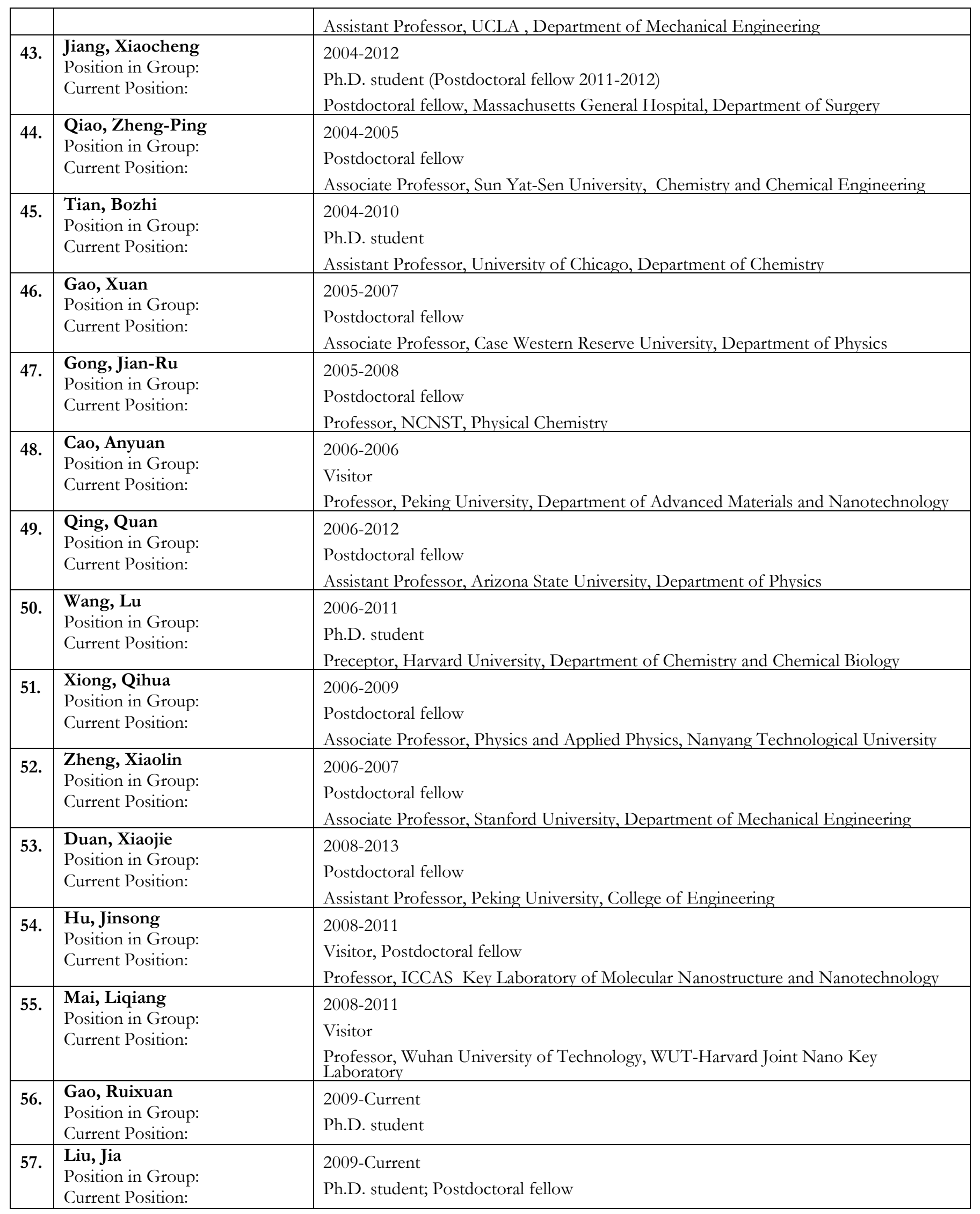




\begin{tabular}{|c|c|c|}
\hline 58. & $\begin{array}{l}\text { Yu, Zhe } \\
\text { Position in Group: } \\
\text { Current Position: }\end{array}$ & $\begin{array}{l}2010 \\
\text { Postdoctoral fellow } \\
\text { Associate Professor, Shenzhen Institutes of Advanced Technology, CAS }\end{array}$ \\
\hline 59. & $\begin{array}{l}\text { Jiang, Zhe } \\
\text { Position in Group: } \\
\text { Current Position: }\end{array}$ & $\begin{array}{l}\text { 2010-Current } \\
\text { Ph.D. student }\end{array}$ \\
\hline 60. & $\begin{array}{l}\text { Dai, Xiaochuan } \\
\text { Position in Group: } \\
\text { Current Position: }\end{array}$ & $\begin{array}{l}\text { 2011-Current } \\
\text { Ph.D. student }\end{array}$ \\
\hline 61. & $\begin{array}{l}\text { Xu, Lin } \\
\text { Position in Group: } \\
\text { Current Position: }\end{array}$ & $\begin{array}{l}\text { 2011-Current } \\
\text { Visitor, Postdoctoral fellow }\end{array}$ \\
\hline 62. & $\begin{array}{l}\text { Xie, Chong } \\
\text { Position in Group: } \\
\text { Current Position: }\end{array}$ & $\begin{array}{l}\text { 2011-Current } \\
\text { Postdoctoral fellow }\end{array}$ \\
\hline 63. & $\begin{array}{l}\text { Yao, Jun } \\
\text { Position in Group: } \\
\text { Current Position: }\end{array}$ & $\begin{array}{l}\text { 2011-Current } \\
\text { Postdoctoral fellow }\end{array}$ \\
\hline 64. & $\begin{array}{l}\text { Fu, Tian-Ming } \\
\text { Position in Group: } \\
\text { Current Position: }\end{array}$ & $\begin{array}{l}\text { 2011-Current } \\
\text { Ph.D. student }\end{array}$ \\
\hline 65. & $\begin{array}{l}\text { Zhou, Wei } \\
\text { Position in Group: } \\
\text { Current Position: }\end{array}$ & $\begin{array}{l}\text { 2012-Current } \\
\text { Postdoctoral fellow }\end{array}$ \\
\hline 66. & $\begin{array}{l}\text { Gao, Ning } \\
\text { Position in Group: } \\
\text { Current Position: }\end{array}$ & $\begin{array}{l}\text { 2012-Current } \\
\text { Postdoctoral fellow }\end{array}$ \\
\hline 67. & $\begin{array}{l}\text { Cheng, Zengguang } \\
\text { Position in Group: } \\
\text { Current Position: }\end{array}$ & $\begin{array}{l}\text { 2013-2014 } \\
\text { Visiting Ph.D. student, Ying Fang Group, NCNST }\end{array}$ \\
\hline 68. & $\begin{array}{l}\text { Zhou, Tao } \\
\text { Position in Group: } \\
\text { Current Position: }\end{array}$ & $\begin{array}{l}\text { 2013-Current } \\
\text { Ph.D. student }\end{array}$ \\
\hline 69. & $\begin{array}{l}\text { You, Siheng (Sean) } \\
\text { Position in Group: } \\
\text { Current Position: }\end{array}$ & $\begin{array}{l}\text { 2013-Current } \\
\text { Ph.D. student }\end{array}$ \\
\hline 70. & $\begin{array}{l}\text { Zhao, Yunlong } \\
\text { Position in Group: } \\
\text { Current Position: }\end{array}$ & $\begin{array}{l}\text { 2014-Current } \\
\text { Visiting Ph.D. student, Liqiang Mai Group, WUT }\end{array}$ \\
\hline 71. & $\begin{array}{l}\text { Hong, Guosong } \\
\text { Position in Group: } \\
\text { Current Position: }\end{array}$ & $\begin{array}{l}\text { 2014-Current } \\
\text { Postdoctoral fellow }\end{array}$ \\
\hline 72. & $\begin{array}{l}\text { Gao, Teng } \\
\text { Position in Group: } \\
\text { Current Position: }\end{array}$ & $\begin{array}{l}\text { 2014-Current } \\
\text { Postdoctoral fellow }\end{array}$ \\
\hline
\end{tabular}

